Oecologia Australis

16(3): 540-565, Setembro 2012

http://dx.doi.org/10.4257/oeco.2012.1603.13

\title{
VÍRUS ENTÉRICOS NA LAGOA RODRIGO DE FREITAS
}

Carmen Baur Vieira ${ }^{*}$, Anna Carolina de Oliveira Mendes ${ }^{2}$, Jaqueline Mendes de Oliveira ${ }^{2}$, Ana Maria Coimbra Gaspar ${ }^{2}$, José Paulo Gagliardi Leite ${ }^{1} \&$ Marize Pereira Miagostovich $^{1}$

${ }^{1}$ Fundação Oswaldo Cruz (FIOCRUZ), Instituto Oswaldo Cruz (IOC), Laboratório de Virologia Comparada e Ambiental (LVCA). Avenida Brasil, 4365, Manguinhos, Rio de Janeiro/RJ, Brasil. CEP: 21040-900.

${ }^{2}$ Fundação Oswaldo Cruz (FIOCRUZ), Instituto Oswaldo Cruz (IOC), Laboratório de Desenvolvimento Tecnológico em Virologia (LDTV). Avenida Brasil, 4365, Manguinhos, Rio de Janeiro/RJ, Brasil. CEP: 21040-900.

E-mails: c.baur@ioc.fiocruz.br, annacom@ioc.fiocruz.br, jackie@ioc.fiocruz.br, amgaspar@ioc.fiocruz.br, jpgleite@ioc.fiocruz.br, marizepm@ioc. fiocruz.br

\section{RESUMO}

Os vírus são atualmente considerados importantes contaminantes de águas superficiais, embora ainda não estejam incluídos nos parâmetros de balneabilidade avaliados para exposição humana em águas. Este estudo tem como objetivo avaliar a contaminação pelos principais agentes etiológicos da gastrenterite viral aguda [rotavírus espécie A (RVA) e norovírus (NoV)], adenovírus humanos (HAdV) e vírus da hepatite A (HAV) em águas superficiais da Lagoa Rodrigo de Freitas, Rio de Janeiro, pela detecção, quantificação e caracterização molecular destes agentes, correlacionando-os com parâmetros microbiológicos de qualidade da água. Entre Agosto de 2007 e Julho de 2008, 2L de água superficial foram coletados mensalmente em 12 pontos, incluindo 10 pontos na Lagoa Rodrigo de Freitas, um no Rio dos Macacos e um na praia do Leblon, totalizando 144 amostras. As amostras foram concentradas 1000X pelo método de adsorção-eluição utilizando membrana carregada negativamente e reconcentradas a um volume final de $2 \mathrm{~mL}$ em Centriprep ${ }^{\circledR} \mathrm{YM}-50$. RVA, NoV, HAdV e HAV foram detectados e quantificados pelas técnicas de reação em cadeia pela polimerase convencional e quantitativa (cPCR / qPCR) precedidas por transcrição reversa (RT). Pela análise conjunta destas metodologias, RVA, NoV, HAdV e HAV foram detectados em 24,3\% (35/144), 18,8\% (27/144), 16,7\% (24/144) e 21,5\% (31/144) das amostras estudadas, respectivamente. E.coli foi quantificada por Kit Colilert ${ }^{\circledR}-18$ Quanti-Tray ${ }^{\mathbb{B}} / 2000$ em cada ponto de coleta como um indicador microbiológico de contaminação fecal e $87,5 \%$ (126/144) das amostras foram caracterizadas como próprias a balneabilidade conforme estabelecido pela legislação vigente. RVA, NoV, HAdV e HAV foram detectados em 23,8\% (30/126), 16,7\% (21/126), $15,1 \%(19 / 126)$ e $23,0 \%$ (29/126), respectivamente, das amostras consideradas próprias, evidenciando a presença de vírus em águas que estão dentro dos padrões aceitáveis para E.coli. Os dados obtidos neste estudo enfatizam a necessidade do estabelecimento de parâmetros virais para a avaliação da qualidade da água e a necessidade de se disponibilizar protocolos de detecção viral que auxiliem para a adoção de medidas de controle de contaminação ambiental.

Palavras-chave: vírus entéricos; água recreacional; PCR convencional; PCR quantitativa.

\begin{abstract}
ENTERIC VIRUSES IN RODRIGO DE FREITAS LAGOON. Viruses are now considered important contaminants of surface water, although not yet included in the parameters evaluated for human exposure in bathing waters. This study aims to assess contamination of surface waters of Rodrigo de Freitas Lagoon, Rio de Janeiro, by its major etiologic agents of acute viral gastroenteritis [species A rotavirus (RVA) and norovirus $(\mathrm{NoV})$ ], human adenoviruses (HAdV) and hepatitis A virus (HAV) by detection, quantification and molecular characterization of these agents establishing a correlation with microbiological parameters of water quality. From August 2007 to July 2008, 2L of surface water were monthly collected at 12 points, including 10 points in Rodrigo de Freitas Lagoon, one in Macacos River and one in Leblon Beach, with a total of 144 samples.
\end{abstract}


The samples were concentrated $1000 \mathrm{X}$ by an adsorption-elution method using a negatively charged membrane and reconcentrated to a final volume of $2 \mathrm{~mL}$ in Centriprep ${ }^{\circledR}$ YM-50. RVA, NoV, HAdV and HAV were detected and quantified by conventional and quantitative polymerase chain reaction (cPCR / qPCR) preceded by reverse transcription (RT). Overall, RVA, NoV, HAdV and HAV were detected in 24.3\% (35/144), 18.8\% $(27 / 144), 16.7 \%(24 / 144)$ and $21.5 \%$ (31/144) of the samples studied, respectively. E. coli was quantified by Kit Colilert ${ }^{\mathbb{}}-18$ Quanti-Tray ${ }^{\circledR} / 2000$ in each sample as an indicator of fecal contamination and $87.5 \%(126 / 144)$ of the samples were characterized as suitable for bathing as established by current regulation. RVA, NoV, HAdV and HAV were detected in 23.8\% (30/126), 16.7\% (21/126), 15.1\% (19/126) and 23.0\% (29/126) of the samples, respectively, showing the presence of viruses in waters that are within the acceptable standards for E.coli. The data obtained in this study emphasizes the need to establish parameters for the evaluation of viral quality of water and the need to develop viral detection protocols that can assist measures to control the environmental contamination.

Keywords: enteric viruses; recreational water; conventional PCR; quantitative PCR.

\section{RESUMEN}

VIRUS ENTÉRICOS EN LA LAGUNA RODRIGO DE FREITAS. Los virus son actualmente considerados importantes contaminantes de las aguas superficiales, aunque aún no estén incluidos en los parámetros evaluados en las aguas de baño para la exposición humana. En el presente estudio se evaluó la contaminación de las aguas superficiales de la Laguna Rodrigo de Freitas, Río de Janeiro, por los principales agentes etiológicos de gastroenteritis viral aguda [rotavirus especie A (RVA) y norovirus (NoV)], adenovirus humano (HAdV) y el virus de la hepatitis A (HAV) por la detección, cuantificación y caracterización molecular de estos agentes, estableciendo una correlación con los parámetros microbiológicos de la calidad del agua. Entre Agosto de 2007 y Julio de 2008, se recolectaron mensualmente 2L de agua superficial en 12 puntos, incluyendo 10 puntos en la Laguna Rodrigo de Freitas, una en el Río dos Macacos y una en la Playa de Leblon, con un total de 144 muestras. Las muestras fueron concentradas 1000X por medio de un método de adsorción-elusión utilizando una membrana cargada negativamente, y se reconcentró a un volumen final de $2 \mathrm{~mL}$ en Centriprep ${ }^{\circledR}$ YM-50. Los RVA, NoV, HAdV y HAV fueron detectados y cuantificados por la reacción en cadena de la polimerasa convencional y cuantitativa (cPCR / qPCR) precedida por la transcripción reversa (RT). En general, los RVA, NoV, HAdV y HAV fueron detectados en un 24,3\% (35/144), 18,8\% (27/144), $16,7 \%(24 / 144)$ y $21,5 \%(31 / 144)$ de las muestras, respectivamente. E. coli fue cuantificada en cada muestra, por medio del Kit Colilert ${ }^{\circledR}-18$ Quanti-Tray ${ }^{\circledR} / 2000$, como un indicador microbiológico de contaminación fecal y el $87,5 \%$ de las muestras (126/144) fueron clasificadas como adecuadas para el baño según lo establecido por la normativa vigente. Los RVA, NoV, HAdV y HAV fueron detectados en un 23,8\% (30/126), 16,7\% (21/126), 15,1\% (19/126) y 23,0\% (29/126) de las muestras, respectivamente, evidenciando la presencia de virus en las aguas que están dentro de los estándares aceptables para E. coli. La información obtenida en este estudio enfatiza la necesidad de establecer parámetros para la evaluación de la calidad viral del agua y de desarrollar protocolos de detección viral que puedan ayudar a adoptar medidas para el control de la contaminación ambiental.

Palabras-clave: virus entéricos; agua recreacional; PCR convencional; PCR cuantitativa.

\section{INTRODUÇÃO}

Mesmo com o progresso em toda área tecnológica, as doenças de veiculação hídrica continuam a ter um grande impacto tanto na saúde pública como na área econômica, em função dos quadros de morbidade e mortalidade gerados por estas. Apesar de projeções apontarem o declínio de quadros infecciosos nos próximos vinte anos, tais projeções não consideram que a maior proporção das doenças infecciosas emergentes é representada por agentes etiológicos de origem viral, uma vez que a melhoria dos padrões de saneamento e de qualidade da água contribuiu para a redução da transmissão da maior parte dos patógenos 
bacterianos. Dentro das enfermidades infecciosas, os vírus são os principais causadores de surtos relacionados à contaminação de água e alimentos nos países desenvolvidos, onde a melhora dos tratamentos e depuração das águas residuais reduziu a transmissão da maior parte dos patógenos bacterianos (Craun 1992, Grabow 2007).

Existem mais de 100 tipos diferentes de vírus encontrados nos dejetos humanos e todos são potencialmente transmitidos pela água (Bosch et al. 2008). Ao contrário da poluição por bactérias e fungos, a presença de partículas virais na água é de difícil detecção e exige tecnologias sofisticadas de concentração destes agentes e, em muitos casos, detecção molecular. Um dos desafios da análise de vírus em amostras de água tem sido a dificuldade em se detectar concentrações normalmente baixas pertencentes a diferentes famílias e que estão dispersos em grandes volumes destas amostras ambientais (Metcalf et al. 1995, Katayama et al. 2002, Bosch et al. 2008).

Os primeiros estudos sobre a dispersão dos vírus no ambiente aquático tiveram início na década de 40, com a tentativa de se detectar poliovírus pela inoculação de águas de esgoto em macacos (Melnick 1947). A partir da década de 80 , a virologia ambiental ganhou impulso em função do desenvolvimento e aprimoramento de metodologias de concentração e de detecção molecular, que permitiram a obtenção de informações sobre estes patógenos, especialmente daqueles não isolados de forma eficiente em linhagens celulares, como os vírus fastidiosos. Atualmente, a associação de metodologias de concentração e detecção viral, utilizando ferramentas moleculares, tem permitido a avaliação de contaminação viral em diferentes ecossistemas aquáticos (Bosch 1998, Pina et al. 1998, Chapron et al. 2000, Cho et al. 2000, Wyn-Jones et al. 2000, Fout et al. 2003, La Rosa et al. 2007, Miagostovich et al. 2008, Wong et al. 2009).

O lançamento direto de efluentes domésticos em ambientes aquáticos tem sido apontado como o principal aporte de vírus nesses ecossistemas, uma vez que esses microrganismos são excretados em elevadas concentrações pelas fezes de indivíduos infectados. Os tipos e as concentrações dos vírus detectados no esgoto ou em locais contaminados por lançamentos de esgoto sem tratamento demonstram o fluxo dos vírus na população e refletem as infecções virais mais prevalentes na comunidade e o nível de poluição da água.

Os vírus entéricos, transmitidos pela via fecal-oral, são mais resistentes à degradação que os indicadores bacterianos fecais, sendo encontrados em águas onde os níveis bacterianos se apresentam dentro dos padrões de qualidade. Os vírus podem permanecer viáveis durante vários meses em condições adversas. A ausência de envelope lipídico, assim como o fato de que o capsídeo protéico apresenta carga negativa em pH natural das águas (5 a 9), facilitando a sua adsorção aos particulados do meio e conferindo maior proteção contra degradação/inativação química, os torna capazes de resistir aos processos de tratamento de água e esgoto aplicados no controle bacteriano, inclusive cloração (Bosch 1998, Griffin et al. 1999).

Atualmente, a Legislação Brasileira (Ministério da Saúde 2004) demonstra uma possível preocupação em relação à presença de vírus na água no artigo 12 , parágrafo $2^{\circ}$, quando recomenda enfaticamente "para a filtração rápida se estabeleça como meta a obtenção de efluente filtrado com valores de turbidez inferiores a 0,5UT em 95\% dos dados mensais e nunca superiores a 5,0 UT" a fim de "assegurar a adequada eficiência de remoção de enterovírus, cistos de Giardia spp e oocistos de Cryptosporidium sp." Entretanto, alguns estudos utilizando técnicas moleculares têm permitido observar que a presença de enterovírus não se relaciona com a presença de outros vírus patogênicos e se tem sugerido a utilização de adenovírus humanos (HAdV) como possível indicador viral de contaminação de origem humana (Pina et al. 1998, Formiga-Cruz et al. 2003).

Uma grande variedade de vírus, responsáveis por diferentes enfermidades, tais como a gastrenterite aguda (GA) ou hepatite, já foram detectados em diferentes matrizes aquáticos em estudos realizados em muitos países, incluindo o Brasil. Diferentes metodologias de concentração e detecção viral têm demonstrado a disseminação destes vírus em estuários, rios, mares, lagos e lagoas, águas subterrâneas, potáveis, minerais, recreacionais e em esgotos brutos ou tratados (Kukkula et al. 1999, Pina et al. 2001, Beuret et al. 2002, Vaidya et al. 2002, Van Heerden et al. 2003, Pusch et al. 2005, de Paula et al. 2007, Espinosa et al. 2008, Miagostovich et al. 2008, Ferreira et al. 2009, Hamza et al. 2009, HernandezMorga et al. 2009, Moreno et al. 2009, Wong et al. 
2009, Fumian et al. 2010, Rigotto et al. 2010, Silva et al. 2010, Victoria et al.2010a, 2010b, Lee et al. 2011, Prado et al. 2011, Wyn-Jones et al. 2011).

Dentre os vírus entéricos associados a surtos de veiculação hídrica, estão os rotavirus espécie A (RVA), os norovirus (NoV), os HAdV e o vírus da hepatite A (HAV), reconhecidos como os principais agentes etiológicos da gastrenterite infantil aguda e da hepatite entérica, respectivamente. A investigação destes vírus em uma lagoa urbana, utilizada para atividades recreacionais, como a Lagoa Rodrigo de Freitas na cidade do Rio de Janeiro, teve como objetivo principal avaliar a disseminação destes agentes neste ecossistema, que ao longo dos anos vem sofrendo com o aporte incessante de águas servidas e de matéria sólida, o que prejudicou a qualidade de suas águas (Alves et al. 1998). Com este propósito estes vírus foram detectados, quantificados e caracterizados molecularmente em concentrados de águas superficiais da lagoa e de ecossistemas associados, como o Rio dos Macacos e a Praia do Leblon, sendo os resultados previamente publicados (Mendes 2009, Vieira 2010, Vieira et al. in press). Este trabalho tem como objetivo reunir os dados obtidos nestes estudos, apresentando uma visão global do estudo de caracterização viral deste ecossistema.

\section{ROTAVÍRUS ESPÉCIE A}

Os rotavírus (RV) são os principais agentes etiológicos da GA em crianças com idade inferior a cinco anos em todo o mundo, sendo responsáveis por aproximadamente $40 \%$ das internações relacionadas à GA (CDC 2008, Chandran et al. 2010).

Descritos pela primeira vez em 1973, em Melbourne, Austrália, os RV pertencem à família Reoviridae, gênero Rotavirus (Bishop et al. 1973, Flewett et al. 1973, Flewett \& Woode 1978). A partícula é não-envelopada, apresenta simetria icosaédrica, mede aproximadamente $100 \mathrm{~nm}$ de diâmetro e é composta por 11 segmentos de RNA fita dupla (RNAfd) (Estes \& Kapikian 2007).

OsRV sãoclassificados em sete sorogrupos distintos (A-G) baseando-se nas propriedades antigênicas da sua proteína estrutural VP6. Os sorogrupos A, B, e C têm sido encontrados em humanos e animais, enquanto os sorogrupos D-G somente em animais (Estes \& Kapikian 2007, Chandran et al. 2010).
A classificação dos RVA em genótipos consiste em um sistema binário baseado na especificidade das proteínas VP7 e VP4. Assim, foram estabelecidos os genótipos/sorotipos G (glicoproteína) e P (sensível a protease) para VP7 e VP4, respectivamente, sendo descritos até o momento 19 genótipos Ge 27 genótipos P (Ciarlet et al. 2008, Matthijnssens et al. 2008a, 2008b). Recentemente, Matthijnssens et al. (2008a, 2008b) propuseram um novo sistema de classificação para os RVA, tendo como base as propriedades moleculares dos 11 segmentos de RNAfd. Análises filogenéticas sugerem que as características moleculares dos genes que codificam para as proteínas VP1 (RNA-dependent RNA polymerase), VP2 (Core Protein), VP3 (Methyltransferase), VP6 (Inner Capsid), NSP1 (Interferon Antagonist), NSP2 (NTPase), NSP3 (Translation Enhancer), NSP4 (Enterotoxin) e NSP5 (pHosphoprotein) resultam em 4, 5, 6, 11, 14, 5, 7, 11 e 6 diferentes genótipos, respectivamente.

Em função do genoma segmentado, os genes podem segregar independentemente e gerar partículas com combinações diferentes destes genes e, consequentemente, de suas proteínas. Mais de 40 combinações G-P já foram descritas, entretanto estudos de epidemiologia molecular de RVA têm demonstrado que são cinco os genótipos mais comumente detectados no mundo: G1P[8], G2P [4], G3P[8], G4P[8] e G9P[8] (Santos \& Hoshino 2005).

As infecções por RVA produzem quadros infecciosos que vão desde casos assintomáticos, principalmente em adultos, a casos graves de diarréia, que acometem principalmente crianças menores de dois anos. Casos graves em adultos podem ocorrer devido às infecções por genótipos não usuais ou por concentrações extremamente elevadas de partículas virais. A diarréia é a principal manifestação clínica, porém sintomas como vômito, dores abdominais e desidratação, sendo este último o principal fator de mortalidade do hospedeiro, podem ser observados. O período de incubação pode variar de 12 a 48 horas e a doença é autolimitada, normalmente após cinco dias do início da infecção, podendo chegar a 10, o quadro se resolve (Estes \& Kapikian 2007, Greenberg \& Estes 2009). A eliminação de partículas virais pelas fezes inicia-se antes ou após o término da diarréia e pode levar de quatro a 57 dias, com média de 10 dias (Richardson et al. 1998). 
A epidemiologia dos RVA é complexa, com variados estudos apontando diversos genótipos $\mathrm{P}$ e G de RVA co-circulando dentro de uma mesma região, com prevalências alternadas anualmente de um dado genótipo em uma determinada região. Outra observação é que os genótipos prevalentes em diferentes regiões de um país podem ser diferentes dentro do mesmo período epidêmico (Pérez-Vargas et al. 2006).

Vacinas anti-RVA tem sido desenvolvidas ao longo de duas décadas. A vacina $\operatorname{Rotarix}^{\circledR}$, desenvolvida pela GlaxoSmithKline Biologicals, de especificidade genotípica G1P[8], foi introduzida no Programa Nacional de Imunização (PNI) em março de 2006, porém já estava disponível desde 2005 em clínicas e consultórios particulares (Carvalho-Costa et al. 2011).

Linhares et al. (1977) descreveram o primeiro relato de casos de gastrenterite infantil aguda associado aos RVA na América Latina, observando por microscopia eletrônica (ME) partículas semelhantes aos RV em fezes de crianças com diarréia aguda em Belém do Pará, Brasil. Desde então, diversos outros trabalhos têm sido publicados demonstrando os casos de GA associados aos RV no país. Em uma extensa revisão dos artigos que descrevem a genotipagem de RVA circulantes no Brasil em dois períodos pré-vacinais compreendidos entre 1982-1995 e 1996-2005, Leite et al. (2008) demonstraram que as combinações mais frequentemente encontradas foram: G1P[8]/G1P[NT] (43\%), G9P[8]/ G9P[NT] (20\%), G2P[4]/ G2P[NT] (9\%), G3P[8]/ G3P[NT] (6\%), G4P[8]/ G4P[NT] (4\%) e G5P[8]/ G5P[NT] (4\%). A partir de 2005, foi observada a reemergência do genótipo G2P[4] no país, com predominância desse genótipo no período de 2006 a 2008. O mesmo ocorreu após a introdução da vacina em outros países, o que levou a especulação sobre a relação da vacinação com essa reemergência. Entretanto, o genótipo G2P[4] também foi detectado em países em que não havia sido implementada a vacinação contra os RVA e estudos apontaram que esta reemergência estaria associada a flutuações naturais na distribuição dos genótipos dos RVA (CarvalhoCosta et al. 2011).

\section{NOROVIRUS}

Os NoV são responsáveis por cerca de $50 \%$ dos surtos de gastrenterite em todo o mundo, correspondendo a aproximadamente $93 \%$ das gastrenterites não-bacterianas (Patel et al. 2009). Estima-se que os NoV sejam responsáveis por 64.000 episódios diarréicos que requerem hospitalização, 900.000 consultas clínicas em crianças de países industrializados e acima de 200.000 óbitos de crianças com idade inferior a cinco anos em países em desenvolvimento (Patel et al. 2008).

$\mathrm{O} \mathrm{NoV}$ pertence à família Caliciviridae, gênero Norovirus, e foi o primeiro vírus descrito como causador da GA, quando foi detectado por ME em amostras de um surto de gastrenterite em crianças de uma escola primária na cidade de Norwalk, Ohio, Estados Unidos (Kapikian et al. 1972). O gênero Norovirus está dividido em cinco genogrupos (GI-GV) baseando-se na análise da seqüência de informação obtida da região que codifica a proteína de capsídeo VP1, sendo os genogrupos I, II e IV responsáveis por infecções em humanos. Os G são constituídos de genótipos (GG), que representam a unidade mínima de classificação dos NoV. Até o momento foram descritos oito GG no GI e 20 no GII (Zheng et al. 2006, Patel et al. 2009).

$\mathrm{O}$ genoma dos NoV é composto de um RNA fita simples (RNAfs) com polaridade positiva e sua partícula é não-envelopada, apresenta simetria icosaédrica, mede aproximadamente $40 \mathrm{~nm}$ de diâmetro e apresenta 32 depressões em forma de taça na sua superfície (Patel et al. 2009).

As infecções por NoV são caracterizadas por diarréia e vômito. Essas manifestações podem estar acompanhadas por náusea, câimbras abdominais, cefaléia, febre e mialgia (Thornton et al. 2004, Bull et al. 2006). Os sintomas manifestam-se de 12 a 72 horas e os vírus são eliminados por um período que pode exceder 22 dias. O período de incubação é de 12 a 48 horas, a doença é geralmente branda e autolimitada, afetando indivíduos de todas as faixas etárias (Clark \& McKendrick 2004, Thornton et al. 2004, Patel et al. 2009).

A principal via de transmissão dos $\mathrm{NoV}$ é fecal-oral, com a infecção primária ocorrendo principalmente pela ingestão de água e alimentos contaminados, resultando em altas taxas de transmissão e grandes surtos. A transmissão também pode ocorrer pelo contato com superfícies contaminadas e pela formação de aerossóis (vômitos) gerando infecções secundárias. A baixa dose infecciosa requerida para ser estabelecida a 
infecção, a eliminação prolongada de partículas nas fezes, a estabilidade no ambiente, a grande diversidade genética e a baixa imunidade contribuem na disseminação de casos e explicam a disseminação rápida e extensa de surtos de doenças em ambientes fechados, como hospitais, hotéis, cruzeiros e creches (Estes et al. 2000, Glass et al. 2000, Fankhauser et al. 2002, Widdowson et al. 2005, Bull et al. 2006, Patel et al. 2009).

Surtos e casos esporádicos de GA associados aos NoV podem ocorrer durante todo o ano, embora se observem diferentes padrões de sazonalidade nos hemisférios norte e sul para a maioria dos surtos. No hemisfério norte, os casos ocorrem com maior frequência no inverno ou na estação seca, enquanto que no sul são mais freqüentes no verão (Froggatt et al. 2004, Parashar et al. 2004, Bon et al. 2005, Fretz et al. 2005, Ike et al. 2006).

Trabalhos desenvolvidos em diversos países do mundo têm demonstrado a importância dos NoV nas GA, especialmente os NoV GII.4, descritos como os mais prevalentes. Além disso, nesses trabalhos podese observar a grande diversidade genética dos $\mathrm{NoV}$ e a descrição de novas cepas circulantes (Vidal et al. 2005, Bon et al. 2005, Okada et al. 2005, Colomba et al. 2006, Ike et al. 2006).

No Brasil, alguns estudos têm demonstrado a importância dos NoV em surtos e/ou em casos esporádicos de gastrenterite infantil aguda (Castilho et al. 2006, Soares et al. 2007, Victoria et al. 2007, Campos et al. 2008, Ferreira et al. 2008, Nakagomi et al. 2008, Ribeiro et al. 2008, Ferreira et al. 2010).

\section{ADENOVÍRUS HUMANOS}

Os HAdV são responsáveis por 7 a $8 \%$ das doenças respiratórias em crianças em todo o mundo e cerca de $10 \%$ de todas as doenças febris que acometem crianças são atribuídas a esses vírus, que são também os patógenos mais associados a infecções oculares (Santos \& Soares 2008).

Os HAdV pertencem à família Adenoviridae, gênero Mastadenovirus. Atualmente, são descritos 51 sorotipos de HAdV (HAdV1-51), subdivididos em 6 espécies $(\mathrm{A}-\mathrm{F})$ de acordo com suas propriedades físico-químicas, imunológicas e bioquímicas, que estão associadas a uma grande variedade de enfermidades, como faringite, amigdalite, bronquite, bronquiolite, pneumonia, conjuntivite, cistite e gastrenterite (Berk 2007).

Os HAdV são vírus não-envelopados, de simetria icosaédrica e apesentam um DNA fita dupla (DNAfd) como material genético. Esses vírus possuem aproximadamente $70-100 \mathrm{~nm}$ de diâmetro e seu capsídeo é composto por 252 capsômeros, dos quais 240 são hexons e 12 são pentons (Berk 2007).

A maioria das doenças causadas por HAdV são agudas e autolimitadas. Embora a fase sintomática possa ser curta, os vírus podem permanecer no trato gastrointestinal e continuam a ser excretados por um período prolongado de tempo (Mena \& Gerba 2008).

Os HAdV foram responsáveis por numerosos surtos em instalações para crianças, como creches, escolas e orfanatos (Chiba et al. 1983, Payne et al. 1984, McMinn et al. 1991), hospitais e centros de saúde (Brummitt et al. 1988, Krajden et al. 1990, McMinn et al. 1991) e instalações militares (Dingle \& Langmuir 1968, Meiklejohn 1983).

A importância dos HAdV e o papel que a água desempenha na sua epidemiologia, assim como o risco que a presença destes patógenos na água traz para o homem, são reconhecidos em todo o mundo (Puig et al. 1994). Sua investigação tem sido importante na avaliação da qualidade viral da água por ser de fácil detecção por métodos moleculares e por apresentarem maior estabilidade em vários tipos de ambientes (água de esgoto, de mar e de abastecimento) que outros vírus entéricos (Puig et al. 1994, Castignolles et al. 1998, Papapetropoulou \& Vantarakis 1998, Gerba et al. 2002).

A aplicação de técnicas moleculares tem permitido identificar adenovírus em praticamente $100 \%$ das amostras de água residuais urbanas analisadas em diversas cidades da África, Estados Unidos, Suécia, França, Grécia e Reino Unido e são os vírus detectados em um maior número de amostras de moluscos bivalves cultivados em águas marinhas com alguma presença de contaminação fecal (Formiga-Cruz et al. 2002). Os adenovírus foram incluídos recentemente na lista de contaminantes candidatos da "United States Environmental Protection Agency" (USEPA), devido a sua grande prevalência em águas residuais, sua relação com diversas patologias, sua resistência no meio ambiente e a alguns dos tratamentos utilizados 
nos processos de depuração de água. A USEPA indica o grupo dos vírus entéricos como o mais seguro e confiável para o monitoramento ambiental (EPA 1988, Van Heerden et al. 2003). Os resultados obtidos sobre a abundância destes vírus e a capacidade de detectar de forma específica a presença de adenovírus de origem humana ou de origem animal (Maluquer de Motes et al. 2004) sugerem sua utilidade como índice molecular de contaminação fecal e como instrumento para se determinar a origem da contaminação.

\section{VÍRUS DA HEPATITE A}

O HAV está classificado na família Picornaviridae como representante único do gênero Hepatovirus. A partícula viral, não-envelopada, apresenta simetria icosaédrica e diâmetro de 27 a 32nm (Feinstone et al. 1973, Winokur et al. 1991, Winokur \& Stapleton 1992). Como os demais membros da família Picornaviridae, o HAV possui genoma RNAfs com polaridade positiva, de 7,5kb. Uma única fase de leitura aberta (ORF), composta por três regiões distintas (P1, P2 e P3), é traduzida em uma única poliproteína de 2.225 a 2.227 aminoácidos (Cohen et al. 1987).

O HAV causa infecção autolimitada com manifestações clínicas variáveis - desde uma infecção assintomática ou inaparente a quadros mais graves podendo, inclusive, levar à morte por insuficiência hepática aguda fulminante. A probabilidade de desenvolvimento de doença clinicamente aparente a partir da infecção por HAV aumenta com a idade (Nainan et al. 2006). Em adultos e crianças maiores, a infecção é geralmente sintomática com presença de icterícia em $>70 \%$ dos pacientes (Lednar et al. 1985).

O HAV é transmitido por via fecal-oral e tem como principal modo de transmissão o contato próximo com pessoas infectadas e a ingestão de alimentos ou água contaminados. Altas concentrações do vírus são eliminadas nas fezes dos indivíduos infectados (até $10^{11}$ partículas virais/g). Condições precárias de higiene e saneamento facilitam a transmissão do vírus devido à alta resistência do HAV em ambiente aquático e são frequentemente associadas a surtos (Bosch et al. 1991, Halliday et al. 1991).

A hepatite A é uma doença de distribuição global, apresentando pelo menos três padrões epidemiológicos classificados de acordo com as condições socioeconômicas e sanitárias das diferentes regiões geográficas (Gust 1992, Melnick 1995). O primeiro padrão é apresentado pelos países com condições sanitárias precárias, onde a maioria das crianças se infecta nos primeiros anos de vida e desenvolve a forma assintomática da doença e acima de 10 anos a população é imune ao HAV em quase sua totalidade. No segundo padrão estão os países desenvolvidos, onde as barreiras ambientais impedem o contato com o vírus na infância, resultando em um grande número de adultos suscetíveis que podem se contaminar a qualquer exposição ao vírus, sendo a infecção sintomática mais freqüente. $\mathrm{O}$ terceiro padrão ocorre nos países em desenvolvimento, apresentando melhorias nas condições de higiene e saneamento.

Melhorias nas condições socioeconômicas e no padrão sanitário possuem um reflexo no padrão de endemicidade da infecção pelo HAV. Nas últimas décadas, houve mudanças na epidemiologia da hepatite A, migrando de um padrão endêmico de alta para um de endemicidade intermediária em diversas regiões, principalmente nos grandes centros urbanos (Vitral et al. 2006, 2008). No Brasil, a região Sudeste apresenta as menores taxas de soroprevalência da infecção pelo HAV. No estado do Rio de Janeiro, Vitral et al. $(2006,2008)$ assinalam que as mudanças na prevalência do HAV vêm ocorrendo independente do nível sócio-econômico da população. O principal aspecto epidemiológico resultante da diminuição da prevalência do HAV representa o aumento no número de indivíduos de grupos etários mais elevados suscetíveis à infecção (Vitral et al. 1998). Como resultado, observa-se um aumento na freqüência de casos clínicos mais graves de hepatite A aguda, além da possibilidade da ocorrência de surtos da doença (Cuthbert 2001).

\section{MATERIAL E MÉTODOS}

\section{AREA DE ESTUDO}

A Lagoa Rodrigo de Freitas, localizada na zona sul da cidade do Rio de Janeiro, possui um espelho d'água de $2,2 \mathrm{~km}^{2}$, profundidade média de $2,8 \mathrm{~m}$ e $7,8 \mathrm{~km}$ de perímetro, com volume de aproximadamente $6.200 .000 \mathrm{~m}^{3}$. Liga-se ao mar pelo canal do Jardim de Alah, que possui $800 \mathrm{~m}$ de comprimento e entre 10 e 18 metros de largura. A sua bacia hidrográfica é formada basicamente pelos 
rios dos Macacos e Cabeça, que desembocam na rua Gal. Garzon, e pelo rio Rainha, que deságua no canal da Av. Visconde de Albuquerque (INEA 2009).

A Lagoa está localizada na malha urbana de uma área de alta densidade populacional na cidade e recebeu despejos domésticos por longo período, e ainda os recebe acidentalmente, gerando alterações em seu ecossistema. Melhorias de expansão da rede coletora (galeria de cintura) empreendidas eliminaram parte desses despejos em tempo seco. Atualmente o grupo de trabalho desenvolve ações visando à revitalização da vertente sul da serra da Carioca (INEA 2009, Projeto Ambiental Lagoa Limpa 2009).

A Lagoa Rodrigo de Freitas se inclui na categoria de lagoa sufocada, por apresentar uma única via de comunicação com o mar. Devido à ineficiente troca de suas águas com o mar, faz-se longo o tempo de residência de suas águas, o que gera um acúmulo de materiais em suspensão e matéria orgânica que aí aportam (INEA 2009).

\section{COLETA}

Para avaliação da disseminação viral na Lagoa Rodrigo de Freitas (água salobra), foram realizadas coletas mensais de $2 \mathrm{~L}$ de água superficial no período de Agosto de 2007 a Julho de 2008. Os pontos de coleta foram determinados utilizando-se o sistema de posicionamento global GPS (Garmin etrex ${ }^{\circledR}$ Legend, EUA) e escolhidos de maneira que todo o entorno lagunar fosse representado, incluindo áreas de lazer e prática de esportes, além de um ponto central, um ponto no Rio dos Macacos (água doce) e um ponto na Praia do Leblon (água salgada), próximo à saída do canal de Jardim de Alah (Figura 1).

\section{CONCENTRAÇÃO VIRAL}

As amostras foram concentradas por metodologia baseada na adsorção-eluição dos vírus em membrana carregada negativamente, descrita por Katayama et al. (2002).

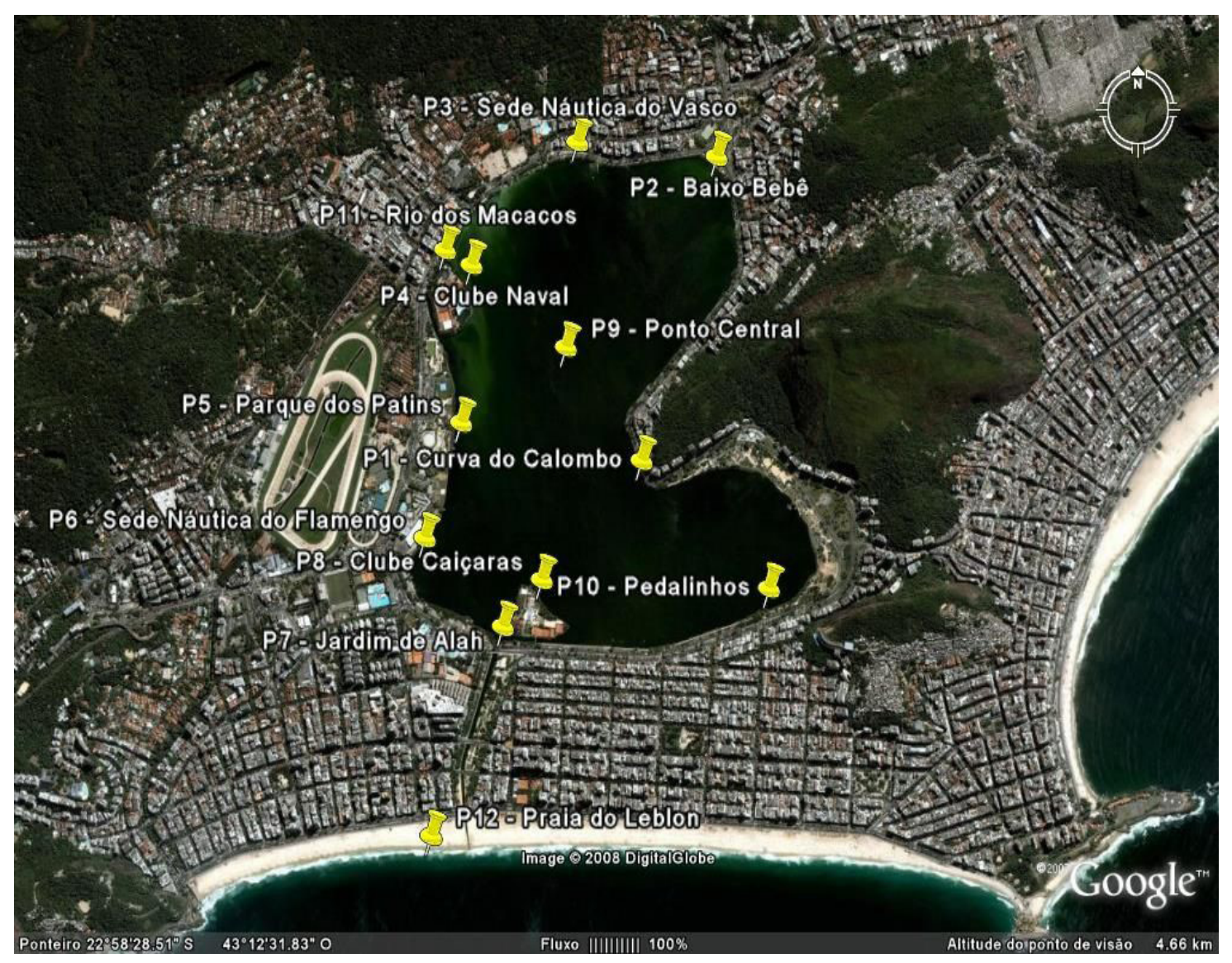

Figura 1. Mapa geográfico da Lagoa Rodrigo de Freitas, município do Rio de Janeiro, RJ: localização dos pontos de coleta (Mendes 2009, Vieira 2010, Vieira et al. in press).

Figure 1. Geographical map of Rodrigo de Freitas Lagoon, Rio de Janeiro, RJ: water sample collection sites (Mendes 2009, Vieira 2010, Vieira et al. in press). 
As amostras foram previamente clarificadas para a remoção de resíduos grosseiros por filtração com pré-filtro AP- $20^{\circledR}$ (membrana de $142 \mathrm{~mm}$ de diâmetro, Millipore $^{\circledR}$, Brasil) utilizando um Sistema de Filtração Millipore (Millipore ${ }^{\circledR}$, Brasil), constituído por uma bomba de vácuo, um recipiente de pressão e um suporte de membranas (Figura 2).

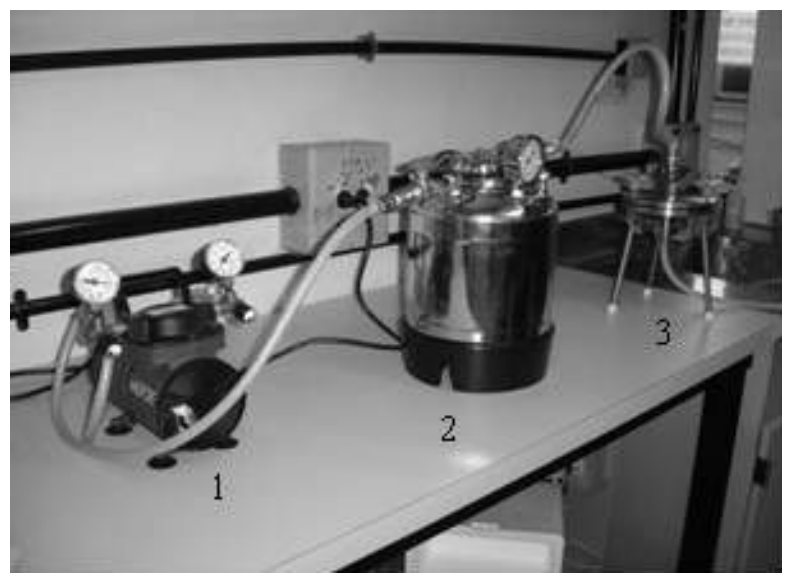

Figura 2. Sistema de filtração Millipore ${ }^{\circledR}$. 1 - Bomba de vácuo com manômetros; 2 - Recipiente de pressão; 3 - Suporte de membranas.

Figure 2. Millipore ${ }^{\circledR}$ filtration system. 1 -Vacuum pump; 2 - Pressure vessel; 3 - Support of membranes.

Após a clarificação, foram adicionados às amostras $25 \mathrm{~mL}$ de cloreto de magnésio $\left(\mathrm{MgCl}_{2}\right.$, Vetec, Brasil) a uma concentração final de $25 \mathrm{mM}$. O pH foi ajustado para 5,0 com a adição de ácido clorídrico $6 \mathrm{~N}(\mathrm{HCl}$, Merck, Brasil). Em seguida, as mesmas foram filtradas em membrana HA carregada negativamente ( $142 \mathrm{~mm}$ de diâmetro, malha de $0,45 \mu \mathrm{m}$, Millipore $^{\circledR}$, Brasil) acoplada ao suporte do sistema de filtração. A membrana foi rinsada com $350 \mathrm{~mL}$ de ácido sulfúrico $0,5 \mathrm{mM}\left(\mathrm{H}_{2} \mathrm{SO}_{4}\right.$, Merck, Brasil). Os vírus foram eluídos em $15 \mathrm{~mL}$ de hidróxido de sódio $3 \mathrm{mM}$, pH 10,5 ( $\mathrm{NaOH}$, Vetec, Brasil) por agitação em placa de petri durante 10 minutos. O eluato foi neutralizado pela adição de $50 \mu \mathrm{L}$ de $\mathrm{H}_{2} \mathrm{SO}_{4} 50 \mathrm{mM}$ e $50 \mu \mathrm{L}$ de tampão Tris-EDTA (TE) 100x $(10 \mu \mathrm{M}$ Tris, 1mM EDTA, pH 8,0) e transferido para uma unidade do concentrador Centriprep ${ }^{\circledR} \mathrm{YM}$ 50 (Millipore, Brasil) (Figura 3). Em seguida, foi realizada centrifugação a $1500 x g$ por 10 minutos a $4^{\circ} \mathrm{C}$, até ser obtido um volume final de $2 \mathrm{~mL}$.

\section{DETECÇÃO VIRAL}

O material genético viral foi extraído das amostras concentradas utilizando-se o conjunto de reagentes comercial "QIAamp Viral RNA Mini Kit" (Qiagen, Valencia, Espanha), seguindo as recomendações do fabricante. Foram utilizados controles negativo e positivo ao longo de todo o processamento da amostra.

A síntese do DNA complementar (cDNA) de RVA, NoV e HAV foi realizada utilizando-se o iniciador randômico $\mathrm{pd}(\mathrm{N})_{6}$ (Amersham Biosciences, EUA) (Ferreira et al. 2009).

Para detecção viral foram realizados protocolos de reação em cadeia pela polimerase convencional (PCR) e quantitativa em tempo real (qPCR) previamente estabelecidos (Tabela 1). HAdV foram pesquisados somente por qPCR por serem estudados como possíveis marcadores virais de contaminação fecal humana.

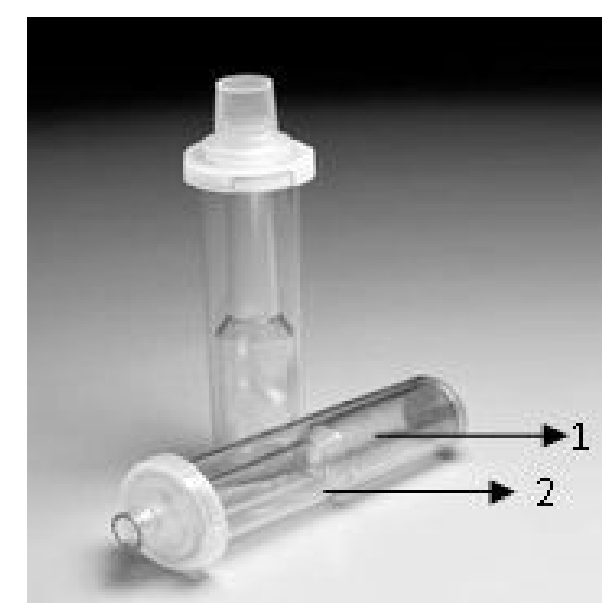

Figura 3. Concentrador Centriprep ${ }^{\circledR}$ YM-50, Millipore ${ }^{\circledR}$. 1-Tubo coletor; 2- Recipiente externo para a amostra.

Figure 3. Centriprep YM-50 ${ }^{\circledR}$ Concentrator, Millipore ${ }^{\circledR}$. 1-Collection tube; 2-Outer container for the sample.

\section{CARACTERIZAÇÃO MOLECULAR}

Para o sequenciamento nucleotídico foram utilizados os amplicons obtidos pela PCR convencional (Tabela 1). Os produtos foram purificados utilizando o kit comercial QIAquick ${ }^{\circledR}$ PCR Purification kit (QIAGEN, Valencia, CA, EUA) ou QIAquick ${ }^{\circledR}$ Gel Extraction kit (QIAGEN, Valencia, CA, EUA). Após a purificação, os produtos foram quantificados em espectrofotômetro NanoDrop ${ }^{\mathrm{TM}}$ (Thermo Scientific, EUA).

Para o sequenciamento direto dos produtos amplificados e purificados foi utilizado o kit comercial "Big Dye Terminator ${ }^{\circledR}$ v3.1 Cycle Sequencing Kit" (Applied Biosystems ${ }^{\circledR}$, CA, EUA), conforme recomendações do fabricante. Foram 
Tabela 1. Protocolos de amplificação genômica pela reação em cadeia pela polimerase convencional e quantitativa para detecção de rotavírus espécie A (RVA), norovírus (NoV), adenovírus humanos (HAdV) e vírus da hepatite A (HAV).

Table 1. Genomic amplification protocols for species A rotavirus (RVA), norovirus (NoV), human adenovirus (HAdV) and hepatitis A virus (HAV) detection by conventional and quantitative polymerase chain reaction.

\begin{tabular}{lccc}
\hline Virus & PCR & Região do genoma & Referência \\
\hline RVA & RT-PCR & VP6 & Iturriza-Gómara et al. 2002 \\
& RT-qPCR & NSP3 & Zeng et al. 2008 \\
Semi-Nested RT-PCR & Polimerase & Boxman et al. 2006 \\
NoV-GI/GII & RT-qPCR & Junção ORF1-ORF2 & Kageyama et al. 2003 \\
& RT-PCR & VP1 & Vinjé et al. 2004 \\
HAdV & qPCR & & Heim et al. 2003 \\
HAV & Nested RT-PCR & Hexon & De Paula et al. 2002 \\
& RT-qPCR & Junção VP1/2A & Jothikumar et al. 2005 \\
\hline
\end{tabular}

utilizados os mesmos iniciadores de cadeia utilizados na reação de PCR de cada um dos vírus. As reações de sequência e os cromatogramas das sequências foram obtidos a partir do sequenciador automático de 48 capilares "ABI Prism 3730 Genetic Analyzer" (Applied Biosystems, CA, EUA) do serviço da "Plataforma de Sequenciamento de DNA PDTIS/ FIOCRUZ”.

As sequências nucleotídicas foram editadas e alinhadas utilizando o método CLUSTAL W (Thompson et al. 1994), contido no programa BioEdit $^{\circledR}$ (Hall et al. 1999). As sequências protótipos representantes dos diferentes genótipos de RVA e HAV de origem humana e animal, descritas em diferentes países, foram resgatadas no site do NCBI (National Center for Biotechnology Information - http://www.ncbi.nlm.nih.gov) através dos seus números de acesso ou mediante a utilização da ferramenta BLAST (Basic Local Aligment Search Tool), disponível no Genbank.

As relações filogenéticas entre as diferentes sequências foram determinadas mediante a utilização do pacote de programas MEGA v.4.0 (Tamura et al. 2007) através do método de reconstrução filogenética Neighbor-joining. As distâncias genéticas entre as diferentes amostras foram calculadas mediante o modelo Kimura-dois-parâmetros como modelo de substituição nucleotídica. A significância estatística das diferentes filogenias obtidas foi estimada através de 2.000 réplicas de bootstrap.

\section{PARÂMETROS MICROBIOLÓGICOS}

Para a quantificação de Escherichia coli (E. coli) foi utilizado o Kit Colilert ${ }^{\circledR}-18$ Quanti-Tray ${ }^{\circledR} / 2000$ (IDEXX Laboratories, Westbrook, EUA), seguindo as recomendações do fabricante. Este método baseia-se na observação de fluorescência gerada pela metabolização de nutrientes presentes no meio de cultura pela $E$. coli.

O processamento das amostras foi realizado dentro de até 2 horas após a coleta e foram necessárias diluições seriadas das mesmas. As amostras coletadas nos dez pontos do entorno da Lagoa e no ponto da Praia do Leblon foram analisadas nas diluições $10^{\circ}$, $10^{-1}$ e $10^{-2}$. As amostras da desembocadura do Rio dos Macacos foram analisadas nas diluições $10^{-1}$, $10^{-2}$ e $10^{-3}$.

Segundo a Resolução CONAMA $n^{\circ} 274$, de 29 de novembro de 2000, as águas destinadas a balneabilidade (recreação de contato primário) têm sua condição avaliada nas categorias próprias e impróprias baseando-se nos valores obtidos para E. coli. Em função de as coletas serem realizadas mensalmente, considerou-se o parágrafo $4^{\circ}$ do artigo $2^{\circ}$ desta para a análise da água por este parâmetro, que considera amostras próprias aquelas cujos valores obtidos encontram-se abaixo de 2000NMP (número mais provável) de E. coli/100mL.

Para avaliar-se a possível correlação entre a detecção de HAdV como um possível marcador 
viral de contaminação fecal humana e quantificação de E. coli dentro e fora do padrão estabelecido pela legislação vigente, foi realizado o teste qui-quadrado $\left(\chi^{2}\right)$ cuja hipótese nula foi a distribuição homogênea de detecção viral entre as classes microbiológicas $(E$. coli $>2000 \mathrm{NMP} / 100 \mathrm{~mL}$ e $E$. coli $<2000 \mathrm{NMP} / 100 \mathrm{~mL}$ ).

As análises de correlação foram realizadas apenas com as 120 amostras provenientes da Lagoa Rodrigo de Freitas, foco de estudo, em função dos pontos Rio dos Macacos e Praia do Leblon não apresentarem uma amostragem adequada para análise ( $\mathrm{n}=12$ para cada ponto).

\section{RESULTADOS}

Foram realizadas 12 coletas mensais ao longo de um ano em 12 pontos de coleta, incluindo 10 pontos na Lagoa Rodrigo de Freitas, um no Rio dos Macacos, que desemboca na Lagoa, e um na praia do Leblon, onde a água da Lagoa é escoada, totalizando 144 amostras.

As tabelas 2 e 3 apresentam os resultados obtidos pela análise conjunta da metodologia de concentração com as ferramentas moleculares de detecção convencional e quantitativa dos RVA, NoV, HAdV e HAV nos pontos avaliados.

Tabela 2. Detecção de rotavírus espécie A (RVA), norovírus (NoV), adenovírus humanos (HAdV) e vírus da hepatite A (HAV) de acordo com o tipo de matriz aquática (Mendes 2009, Vieira et al. in press).

Table 2. Detection of species A rotavirus (RVA), norovirus (NoV), human adenovirus (HAdV) and hepatitis A virus (HAV) detection according to water samples matrices (Mendes 2009, Vieira et al. in press).

\begin{tabular}{|c|c|c|c|c|c|}
\hline \multirow{2}{*}{$\begin{array}{l}\text { Pontos de coleta } \\
\text { (matriz analisada) }\end{array}$} & \multicolumn{4}{|c|}{ No. de positivas/No. de analisadas (\%) } & \multirow{2}{*}{ Total } \\
\hline & RVA & NoV & HAdV & HAV & \\
\hline $\begin{array}{l}\text { Lagoa Rodrigo de } \\
\text { Freitas } \\
\text { (salobra) }\end{array}$ & $30 / 120(25)$ & $21 / 120(17,5)$ & $20 / 120(16,7)$ & $27 / 120(22,5)$ & $71 / 120(59,2){ }^{* 1}$ \\
\hline $\begin{array}{l}\text { Rio dos Macacos } \\
\text { (doce) }\end{array}$ & $3 / 12(25)$ & $4 / 12(33,3)$ & $2 / 12(16,7)$ & $1 / 12(8,3)$ & $6 / 12(50)^{* 2}$ \\
\hline $\begin{array}{l}\text { Praia do Leblon } \\
\text { (salgada) }\end{array}$ & $2 / 12(16,7)$ & $2 / 12(16,7)$ & $2 / 12(16,7)$ & $3 / 12(25)$ & $7 / 12(58,3)^{* 3}$ \\
\hline Total & $35 / 144(24,3)$ & $27 / 144(18,8)$ & $24 / 144(16,7)$ & $31 / 144(21,5)$ & $84 / 144(58,3)$ \\
\hline
\end{tabular}

Tabela 3. Quantificação de rotavírus espécie A (RVA), norovírus (NoV), adenovírus humanos (HAdV) e vírus da hepatite A (HAV) nas amostras positivas (Mendes 2009, Vieira et al. in press).

Table 3. Quantification of species A rotavirus (RVA), norovirus (NoV), human adenovirus (HAdV) and hepatitis A virus (HAV) in the positive water samples (Mendes 2009, Vieira et al. in press).

\begin{tabular}{lr}
\hline Vírus & Cópias de genoma/litro \\
\hline RVA & $3,0 \times 10^{1}-5,6 \times 10^{4}$ \\
NoV & $1,4 \times 10^{0}-3,2 \times 10^{2}$ \\
HAdV & $1,2 \times 10^{1}-1,2 \times 10^{3}$ \\
HAV & $1,3 \times 10^{4}-2,43 \times 10^{5}$ \\
\hline
\end{tabular}

A distribuição dos vírus investigados, de acordo com os pontos de coleta, demonstra a disseminação destes em todos os pontos estudados (Figura 4).

Após a detecção por amplificação parcial do gene que codifica a proteína VP6 de RVA pela RT$\mathrm{PCR}$, sete amostras positivas foram sequenciadas e classificadas como pertencentes a I2 segundo nova classificação proposta (Figura 5). Os valores de identidade nucleotídica variaram de 98,7 a $99,6 \%$ entre as amostras da Lagoa e de 97,4 a 99,3\% entre as amostra da Lagoa e às provenientes das crianças hospitalizadas por gastrenterites no Rio de Janeiro. Com o objetivo de se realizar a classificação binária 
dos RVA, as amostras positivas foram amplificadas com iniciadores específicos para as regiões codificadoras das proteínas VP4 e VP7. Somente uma amostra apresentou resultado positivo, sendo classificada como P4 (Vieira 2010, Vieira et al. in press).

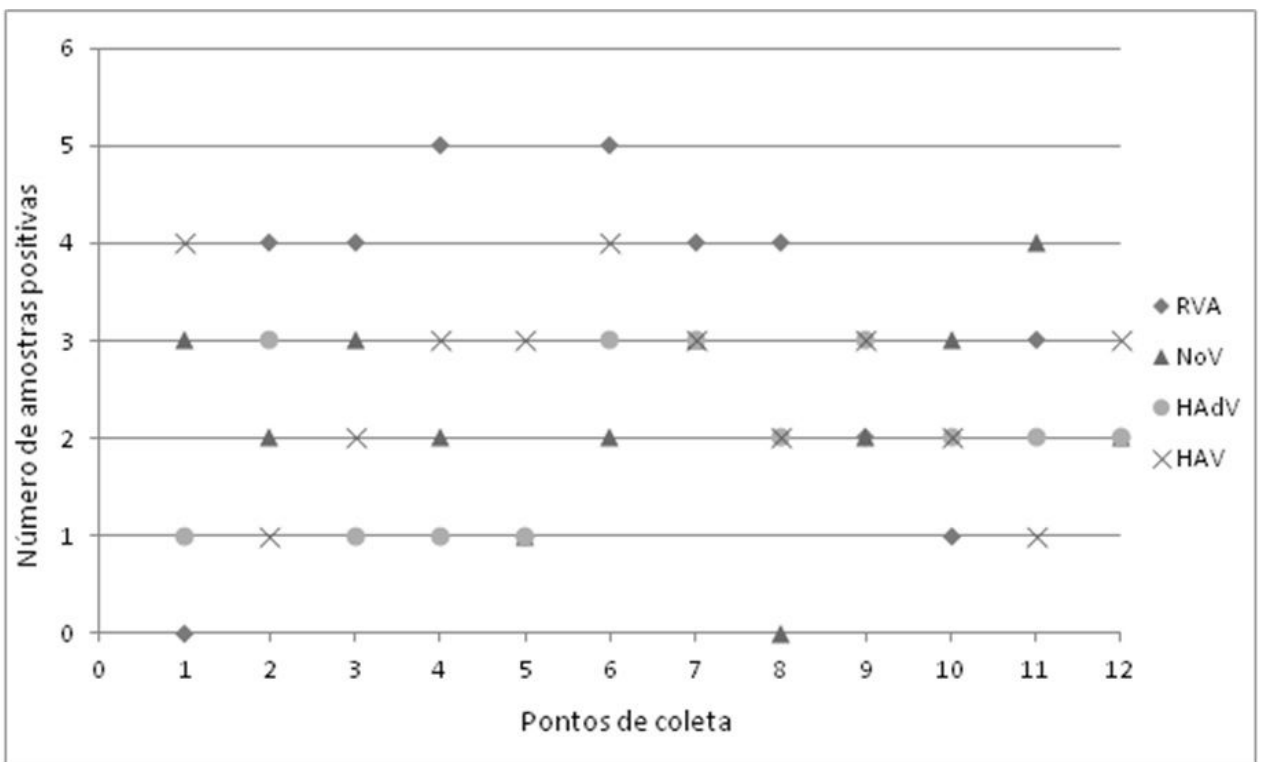

Figura 4. Distribuição de rotavírus espécie A (RVA), norovírus (NoV), adenovírus humanos (HAdV) e vírus da hepatite A (HAV) de acordo com os pontos de coleta. Pontos de coleta: 1- Curva do Calombo; 2- Baixo Bebê; 3- Sede Náutica do Vasco da Gama; 4- Clube Naval; 5- Parque dos Patins;

6- Sede Náutica do Flamengo; 7- Jardim de Alah; 8- Clube Caiçaras; 9- Central; 10- Pedalinhos; 11- Rio dos Macacos; 12 - Praia do Leblon.

Figure 4. Distribution of species A rotavirus (RVA), norovirus (NoV), human adenovirus (HAdV) and hepatitis A virus (HAV) according to collection sites. Collection sites: 1- Curva do Calombo; 2-Baixo Bebê; 3-Sede Náutica do Vasco da Gama; 4- Clube Naval; 5- Parque dos Patins; 6-Sede Náutica do Flamengo; 7- Jardim de Alah; 8-Clube Caiçaras; 9- Central; 10-Pedalinhos; 11-Macacos River; 12- Leblon Beach.

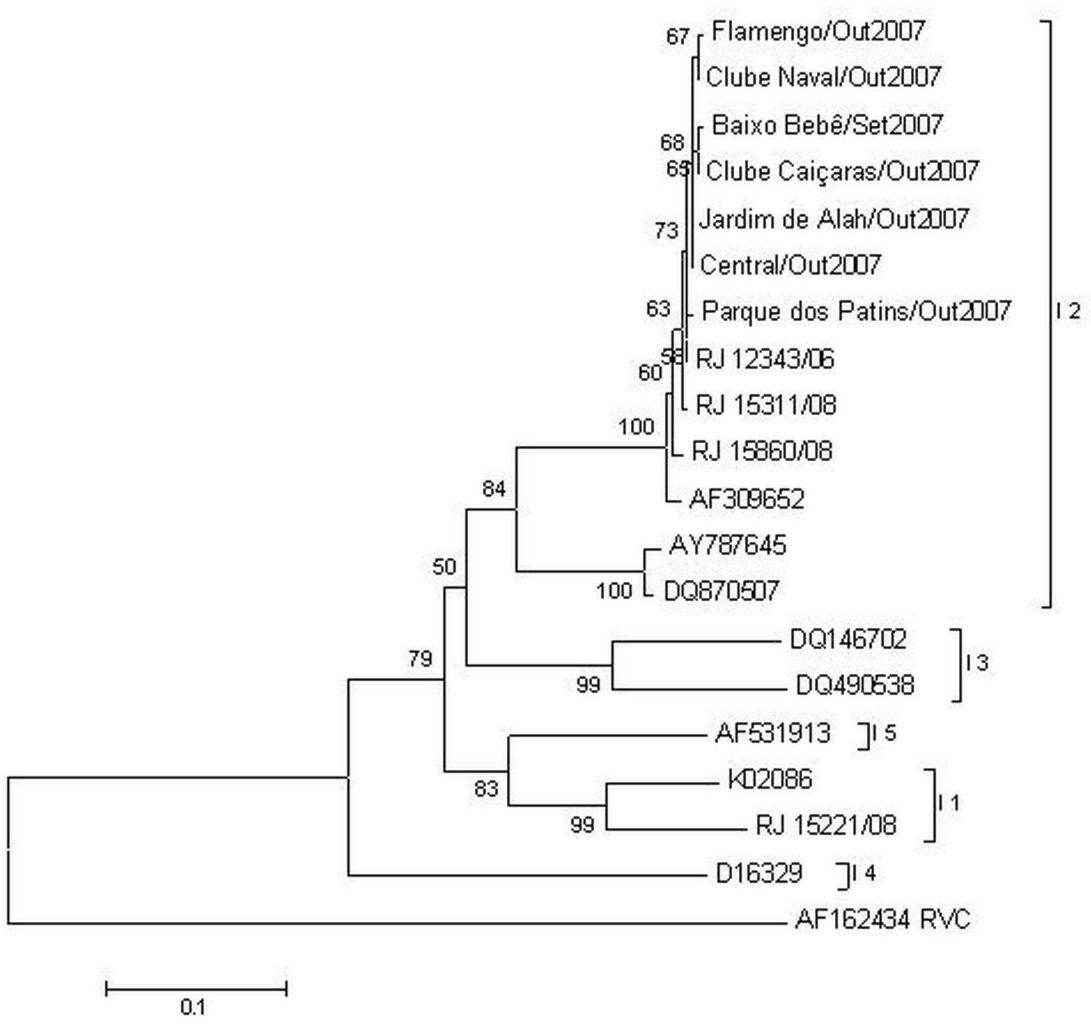

Figura 5. Dendograma de caracterização molecular dos rotavirus espécie A (RVA) a partir do sequenciamento parcial do gene que codifica a proteína VP6 (Vieira 2010).

Figure 5. Dendogram of molecular characterization of species A rotavirus (RVA) obtained from partial sequencing of VP6 protein coding region (Vieira 2010). 
As sequências nucleotídicas dos produtos de nested RT-PCR de 218 pares de bases da região VP1/2A do genoma do HAV de cinco amostras positivas foram determinadas para confirmação e caracterização do genótipo circulante no ambiente lagunar e marinho. As amostras foram classificadas como pertencentes aos genótipos IB (Figura 6), apresentando percentual de identidade nucleotídicas de $92,7 \%$ a $100 \%$ e agruparam com sequências nucleotídicas provenientes de amostras clínicas isoladas no Rio de Janeiro (Mendes 2009).

Considerando o parágrafo $4^{\circ}$ do artigo $2^{\circ}$ da Resolução CONAMA 274 (2000), que considera amostras próprias aquelas cujos valores obtidos encontram-se abaixo de 2000NMP E. coli/100mL, 95\% (114/120) das águas da Lagoa, 16,7\% (2/12) das águas provenientes do Rio dos Macacos e 83,3\% (10/12) da Praia do Leblon foram consideradas próprias, totalizando $87,5 \%(126 / 144)$ de amostras com valores abaixo do estabelecido para este parâmetro (Vieira 2010, Vieira et al. in press). Os pontos do Rio dos Macacos e Jardim de Alah (ponto 7) apresentaram índices mais elevados de contaminação para este parâmetro (Tabela 4).

RVA, NoV, HAdV e HAV foram detectados em $23,8 \%$ (30/126), 16,7\% (21/126), 15,1\% (19/126) e $23,0 \%(29 / 126)$, respectivamente, com um total de $57,1 \%(72 / 126)$ das amostras consideradas

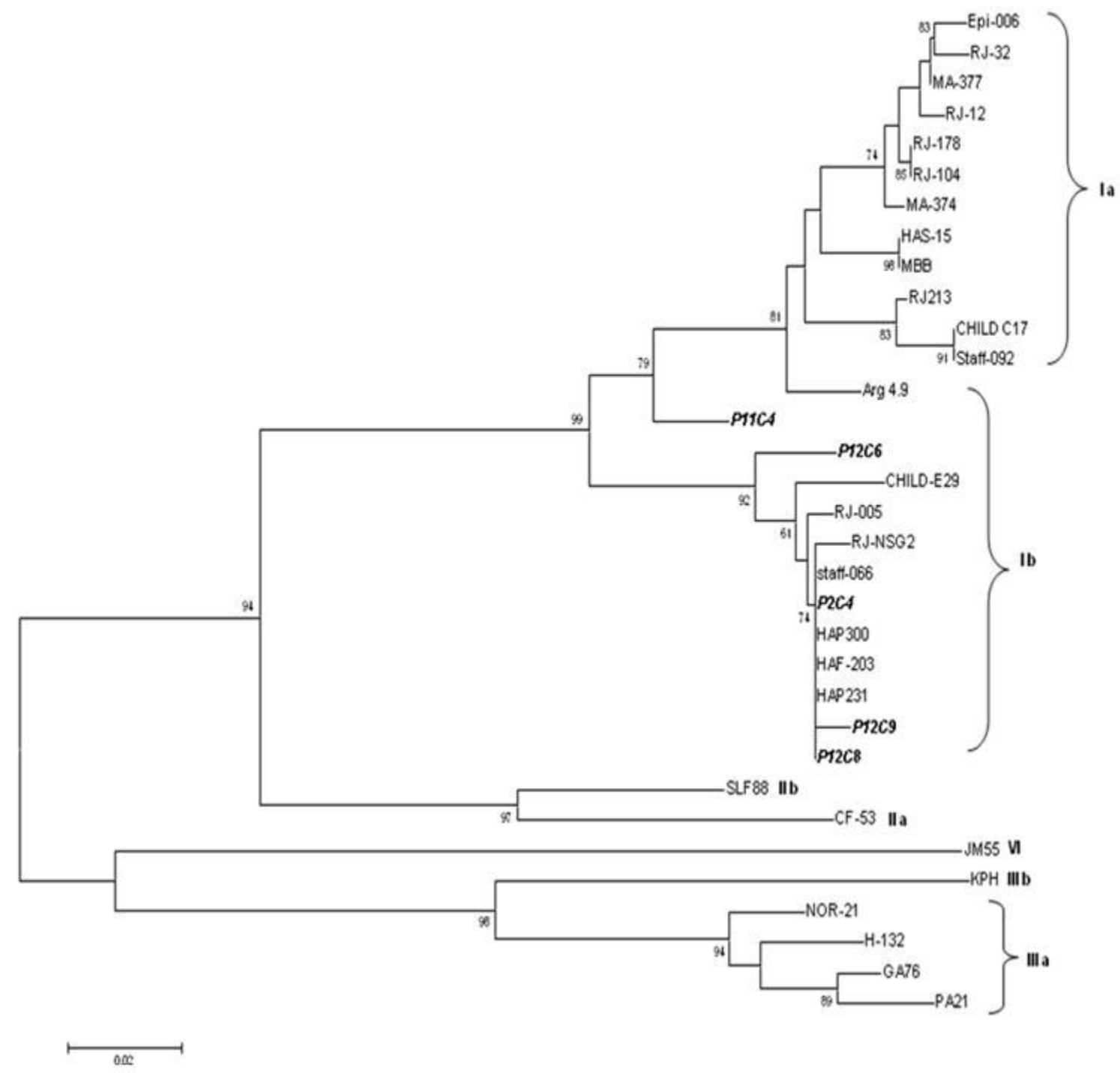

Figura 6. Dendograma construído pela análise filogenética de 218 nucleotídeos da região VP1/2A do genoma do vírus da hepatite A (HAV). As sequências de HAV referentes às amostras de água da Lagoa Rodrigo de Freitas, Rio dos Macacos e Praia do Leblon estão representadas pelas siglas: Lagoa Rodrigo de Freitas (P2C4), Rio dos Macacos (P11C4) e Praia do Leblon (P12C6, P12C8 e P12C9) (Mendes 2009).

Figure 6. Dendogram obtained from the phylogenetic analysis of 218 nucleotide sequencing of hepatitis A virus (HAV) VP1/2A coding region. HAV sequences related to Rodrigo de Freitas Lagoon, Macacos River and Leblon Beach water samples are represented by P2C4 (Rodrigo de Freitas Lagoon), P11C4 (Macacos River) and P12C6, P12C8 and P12C9 (Leblon Beach), (Mendes 2009). 


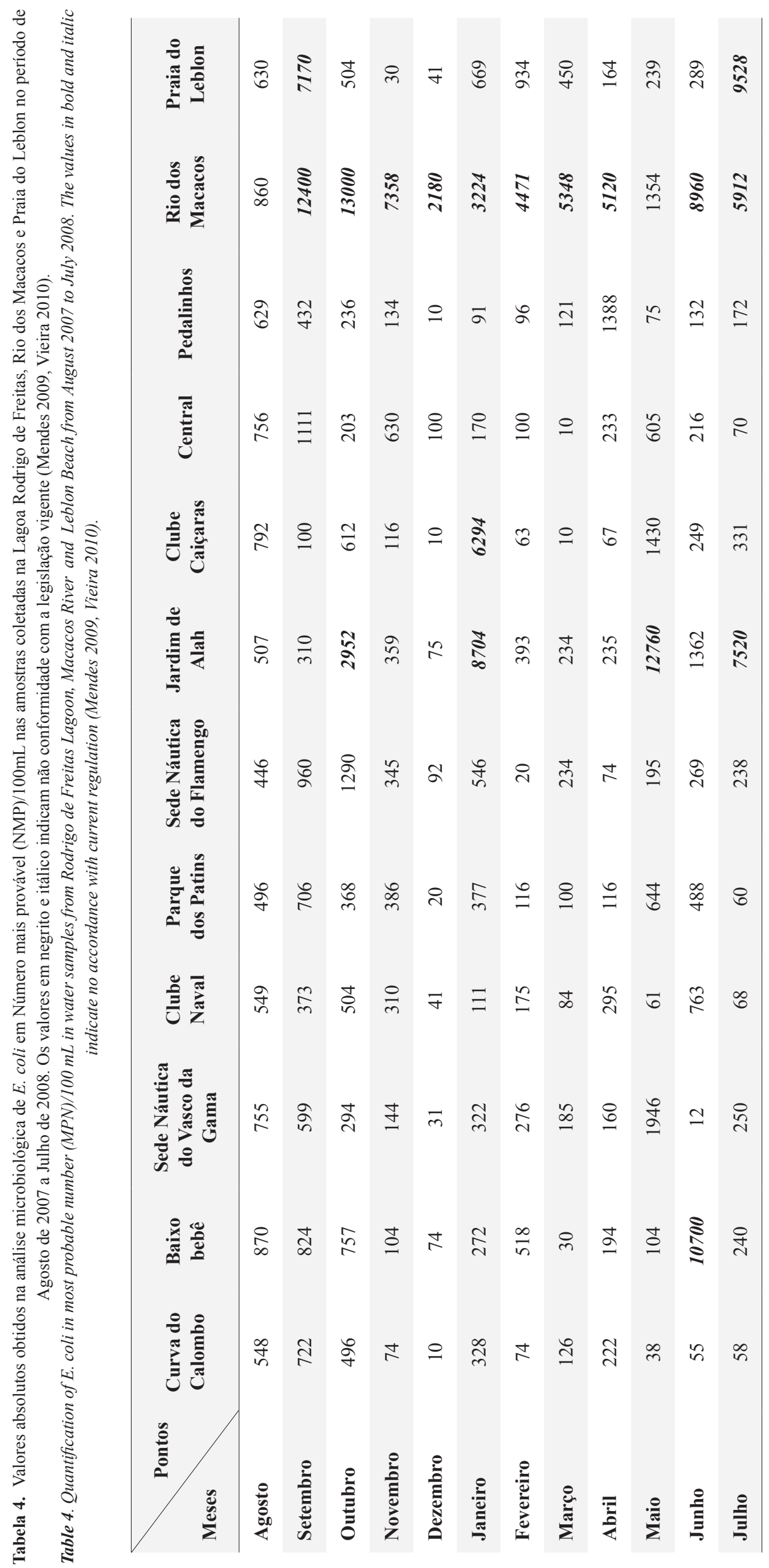


próprias. Considerando o HAdV como um possível marcador viral de contaminação fecal humana, a análise estatística demonstrou uma distribuição não homogênea entre positivos e negativos para HAdV com a classificação da água segundo a análise do parâmetro $E$. coli $(\mathrm{p}<0,01)$, entretanto não se pode afirmar que há uma relação positiva entre valores elevados de E. coli e detecção viral (Mendes 2009, Vieira 2010, Vieira et al. in press).

\section{DISCUSSÃO}

Muitas águas utilizadas para recreação em zonas balneares de todo o mundo estão localizadas próximas a zonas urbanas e, portanto, estão sujeitas à contaminação por dejetos humanos, sendo, por isto, objeto de monitoramento para determinação da qualidade microbiológica da água. A Lagoa Rodrigo de Freitas está situada na zona sul da cidade do Rio de Janeiro e, em função da intensa ocupação urbana em seu entorno, sofreu com o aumento das atividades antropogênicas, ligações clandestinas de esgoto na rede pluvial e lançamentos de esgoto "in natura" diretamente em suas águas.

Indicadores bacterianos de contaminação fecal são utilizados rotineiramente para avaliar a qualidade microbiológica da água. Os resultados obtidos na quantificação de E. coli demonstraram que $87,5 \%$ das amostras estudadas encontravam-se dentro dos padrões de balneabilidade estabelecidos pela legislação vigente, demonstrando que o programa de despoluição estabelecido na Lagoa Rodrigo de Freitas vem gerando melhora na qualidade das suas águas. Os pontos do Rio dos Macacos e Jardim de Alah apresentaram índices mais elevados de contaminação para este parâmetro. Vale lembrar que estes dois ambientes influenciam diretamente a qualidade da água da Lagoa, o primeiro pelo aporte de água doce e carga orgânica e o segundo pela realização do balanço hídrico com o mar. Entretanto, a detecção de vírus em $57,1 \%$ das amostras consideradas próprias a balneabilidade evidencia uma contaminação de origem humana, uma vez que esses vírus são espécie-específicos, não constituem a microbiota gastrointestinal normal e são eliminados em fezes de indivíduos infectados (Abad et al. 1997, Grabow 2007). Estes resultados ressaltam a necessidade de se avaliar o risco de infecção humana, uma vez que a detecção de E. coli dentro dos padrões aceitos para água de recreação não significou a ausência de RVA, NoV, HAdV ou HAV, comprovando que este padrão de qualidade não é suficiente para garantir a qualidade virológica da água. Desta forma, atribuir segurança em termos sanitários para águas de recreação, quando as bactérias indicadoras estão dentro dos padrões considerados satisfatórios, é admitir ou aceitar uma falha, com potencial de risco para a saúde, uma vez que a presença de vírus não pode ser descartada (Gerba et al. 1979, Goyal et al. 1984, Skraber et al. 2004, Jiang 2006, Rose et al. 2006, Rajal et al. 2007, Miagostovich et al. 2008, Espinosa et al. 2009, Silva et al. 2010).

O presente estudo também avaliou o método de concentração viral utilizando filtração por membranas carregadas negativamente em água salobra. Este método foi selecionado por utilizar soluções inorgânicas na eluição viral não apresentando efeito inibitório quando associado às metodologias moleculares de detecção, sendo uma alternativa útil para superar as limitações de técnicas convencionais como culturas de células, recomendado assim para detecção de vírus fastidiosos como os RVA e HAV (Katayama et al. 2002). A detecção de ambos os vírus RNA e DNA revelou que a associação de métodos aqui descritos representa uma abordagem viável para se detectar os principais vírus entéricos responsáveis pela gastroenterite aguda assim como o HAV. Metodologias moleculares de detecção genômica não fornecem informações sobre a infecciosidade da partícula viral, podendo detectar genomas provenientes de partículas infecciosas e/ ou derivados de vírus inativados ou defectivos (Gassilloud et al. 2003, Haramoto et al. 2007, Hamza et al. 2009). Entretanto, a baixa estabilidade do RNA livre no ambiente sugere que estas metodologias detectem partículas virais intactas e não o genoma viral livre da partícula, apesar de o mesmo poder ser detectado mesmo quando os vírus estão inativados por desinfecção química, calor ou proteases presentes na água (Meleg et al. 2006, Carducci et al. 2008). Haramoto et al. (2007) demonstraram que o método de concentração aplicado neste trabalho concentra partículas virais completas preferencialmente a genomas virais livres no ambiente, indicando uma possível infecciosidade destes vírus. Espinosa et al. (2008) sugeriram que a detecção do genoma viral 
pode ser um indicador adequado para a contaminação de águas superficiais, uma vez que encontrou uma correlação entre infecciosidade e detecção do genoma viral.

Até o momento não há relatos na literatura referentes à detecção viral em lagoas de água salobra. Entretanto, estudos em amostras de água de estuários demonstram a circulação de NoV e HAV (Gentry et al. 2009, Hernandez-Morga et al. 2009). A detecção de vírus na Praia do Leblon $(58,3 \%)$ revelou a disseminação destes vírus nesta matriz aquática, assim como demonstrado em outros países (Calgua et al. 2008, Wong et al. 2009, Silva et al. 2010). Vale lembrar, que os percentuais de detecção destes vírus nas diferentes matrizes aquáticas são influenciados não apenas pelo nível de contaminação viral, como também pelos diferentes métodos de recuperação e detecção utilizados.

Alguns estudos têm sugerido os HAdV como indicadores virais de contaminação fecal humana em função de sua disseminação no ambiente, estabilidade em esgotos domésticos e amostras ambientais e resistência aos processos de tratamento de água e esgoto (Puig et al. 1994, van Heerden et al. 2003, Pusch et al. 2005, Bofill-Mas et al. 2006). No presente estudo, foi estatisticamente observada uma distribuição não homogênea de amostras positivas e negativas para HAdV e E. coli, porém não pôde ser afirmada a associação entre eles.

O percentual de detecção de HAdV obtido neste estudo foi inferior aos percentuais encontrados para RVA, NoV e HAV, corroborando dados obtidos por outros trabalhos (Pusch et al. 2005, Miagostovich et al. 2008). Por outro lado, Prado e colaboradores (2011) demonstraram alto percentual de detecção de HAdV (71\% e 85\%) em amostras obtidas no afluente de duas estações de tratamento de esgoto, onde foram detectados RVA (50\%-95\%), HAV (28\%-70\%), NoV-GII (28\%-45\%) e NoV-GI (7\%$10 \%)$.

A análise das sequências nucleotídicas do genoma viral permite a classificação destes em genótipos e subgenótipos distintos, como no caso do HAV. Também demonstra a similaridade dos vírus circulantes em uma determinada região, podendo evidenciar a fonte de contaminação em um surto.
A caracterização molecular dos RVA demonstrou a circulação de amostras I2 de origem humana, segundo nova classificação proposta por Matthijnssens et al. (2008a, 2008b). As sequências nucleotídicas obtidas apresentaram $99 \%$ de identidade nucleotídica com sequências de VP6 de amostras G2P4 (dados não demonstrados). Os RVA I2, detectados em humanos e bovinos, são descritos como associados ao genótipo G2P4, enquanto I1, suínos e humanos, estão associados a G1P8 (Iturriza-Gómara et al. 2002, Lin et al. 2008, Matthijnssens et al. 2008a, 2008b). No Brasil, o genótipo G2P4 vem sendo detectado em elevado percentual em amostras clínicas e tem se apresentado como o mais predominante em amostras de populações vacinadas (Santos \& Hoshino 2005, Leite et al. 2008, Ribeiro et al. 2008). No estado do Rio de Janeiro, segundo levantamento do Laboratório de Virologia Comparada e Ambiental/Instituto Oswaldo Cruz/Fundação Oswaldo Cruz (LVCA/IOC/ FIOCRUZ), Referência Regional em Rotaviroses, os RVA do genótipo G2P4 foram detectados em 57\% e $75 \%$ das amostras clínicas estudadas nos anos de 2007 e 2008, respectivamente. O percentual de identidade nucleotídica observado entre os RVA detectados em amostras provenientes da Lagoa e de espécimes clínicos de casos de GA ocorridos na cidade do Rio de Janeiro demonstra como a abordagem ambiental pode fornecer dados sobre a circulação de um determinado vírus na população.

Para a detecção de NoV, a aplicação de técnicas moleculares vem sendo amplamente utilizada, uma vez que estes vírus não dispõem de cultura celular e modelos animais para sua replicação (Duizer et al. 2004). Descrita como a região mais variável da ORF-2, a região D foi utilizada para caracterização molecular dos NoV em função de apresentar regiões com percentual de identidade que possibilitam a distinção entre genogrupos e genótipos (Vinjé et al. 2004). Dentre as 27 amostras positivas, apenas 10 foram positivas para a região $\mathrm{D}$, sendo que os cromatogramas gerados não permitiram a construção de um dendograma. A grande quantidade de materiais inespecíficos e inibidores presentes nos concentrados de água, a baixa concentração de produtos gerados nos ciclos de amplificação e a não hibridação dos iniciadores com as sequências alvo devido à alta variabilidade genética desta região podem ser 
responsáveis pelos resultados negativos encontrados e pela baixa qualidade das sequências nucleotídicas obtidas.

Dados de sequências nucleotídicas do HAV demonstram que $99 \%$ das amostras foram classificadas como genótipo I e que, embora todas as cinco amostras analisadas nesse estudo tenham sido caracterizadas como subgenótipo IB, apresentam diferenças entre elas, sugerindo a existência de uma variedade de cepas circulantes na Lagoa Rodrigo de Freitas e nas desembocaduras do Rio dos Macacos e da Praia do Leblon. Os genótipos de HAV possuem distribuição geográfica única, sendo o genótipo I o mais prevalente em todo o mundo, e o subgenótipo IA mais comum que o IB (Nainan et al. 2006). Os genótipos IA e IB são frequentemente identificados na América do Norte, América do Sul, Europa, China e Japão (Robertson et al. 1992). No Brasil, o único genótipo que foi encontrado foi o I, principalmente o subgenótipo IA, embora o subgenótipo IB já tenha sido observado nos estados do Rio de Janeiro e Pernambuco e também na região Amazônica (de Paula et al. 2002, 2007, Villar et al. 2004, 2006).

$\mathrm{O}$ risco de transmissão de doenças virais por veiculação hídrica depende da capacidade dos vírus de se manterem infecciosos por um determinado período de tempo até que entrem em contato com um hospedeiro suscetível. Nesse contexto, é fundamental que se realize uma correlação dos dados virológicos com fatores ambientais para avaliação dos efeitos que estes exercem na persistência de partículas virais nestas águas, de modo a se avaliar o potencial risco à saúde pública associado ao seu uso (Ward et al. 1986, Espinosa et al. 2008).

A utilização da água para fins recreativos suscita uma série de riscos para a saúde, que dependem de diversos fatores, como a natureza do perigo, a característica do corpo d'água e o estado imunológico do usuário. Embora evidências obtidas a partir de estudos epidemiológicos e relatórios de surtos tenham demonstrado uma relação entre os efeitos adversos à saúde e a imersão em água de recreação de má qualidade, as dificuldades associadas à atribuição de uma infecção em função do contato com a água são numerosas (Pond 2005). Entretanto, muitos estudos epidemiológicos realizados em águas marinhas e doce têm mostrado que há um aumento significativo na incidência de doenças, incluindo gastrointestinais, de pele, oculares e de ouvido, nas vias respiratórias ou infecção da ferida entre aqueles que se envolvem em atividades aquáticas recreativas (Cabelli et al. 1979, D`Alessio et al. 1981, Cabelli et al. 1982, Seyfried et al. 1985, Craun et al. 2005). Além disso, os sistemas de vigilância de surtos de doenças transmitidas pela água nos EUA e Reino Unido revelaram inúmeros surtos associados a piscinas sem tratamento e águas recreacionais de baixa qualidade ao longo dos anos, a maioria deles associado a quadros de GA (Schets et al. 2010).

Os dados apresentados neste capítulo demonstraram a disseminação de agentes virais na Lagoa Rodrigo de Freitas, no Rio dos Macacos e na Praia do Leblon, enfatizando a necessidade do estabelecimento de parâmetros virais para a avaliação da qualidade da água e a necessidade de se disponibilizar protocolos de detecção viral que auxiliem no monitoramento da qualidade da água, na adoção de medidas de controle de contaminação ambiental, assim como futuros trabalhos de análise de risco como parte dos planos de segurança da água.

AGRADECIMENTOS: Este estudo contou com apoio do Programa de Pós-Graduação em Biologia Celular e Molecular do Instituto Oswaldo Cruz/Fundação Oswaldo Cruz (PGBCM/IOC/FIOCRUZ), da Vice-Presidência de Pesquisa e Laboratórios de Referência (VPPLR)/ FIOCRUZ, do Conselho Nacional de Desenvolvimento Científico e Tecnológico (CNPq) e da Coordenação Geral de Vigilância em Saúde Ambiental/Secretaria de Vigilância em Saúde/Ministério da Saúde (CGVAM/SVS/MS) e está no âmbito das atividades da FIOCRUZ como Centro Colaborador da Organização Pan-Americana da Saúde/ Organização Mundial da Saúde (OPAS/OMS) em Saúde Pública e Ambiental.

\section{REFERÊNCIAS}

ABAD, F.X.; PINTÓ, R.M.; VILLENA, C. \& BOSCH, A. 1997. Astrovirus survival in drinking water. Applied and Environmental Microbiology, 63: 3119-3122.

ALVES, D.T.M.; ARGENTO, M.S.F.; CRUZ, C.B.M. \& ZEE, D. 1998. Qualidade Ambiental da Lâmina d'água da Lagoa Rodrigo de Freitas - RJ. Subsídios aos Estudos de Impactos Ambientais em Lagoas Costeiras. Pp. 79-88. In: IX Simpósio Brasileiro de Sensoriamento Remoto. Santos, SP, Brasil.

BERK, A.J. 2007. Adenoviridae: The Viruses and Their Replication. Pp. 2355-2394. In: D.M. Knipe \& P.M. Howley (eds.). Fields Virology, 5th edition. Lippincott Williams \& Wilkins, Philadelphia, PA. 3091p. 
BEURET, C.; KHOELER D.; BAUMGARTNER, A. \& LUTHI, T.M. 2002. Norwalk-like virus sequences in mineral water: oneyear monitoring of three brands. Applied and Environmental Microbiology, 68: 1925-1931, http://dx.doi.org/10.1128/ AEM.68.4.1925-1931.2002

BISHOP, R.F.; DAVIDSON, G.P.; HOLMES, I.H. \& RUCK, B.J. 1973. Virus particles in epithelial cells of duodenal mucosa from children with acute non-bacterial gastroenteritis. Lancet, 2: 12811283, http://dx.doi.org/10.1016/S0140-6736(73)92867-5

BOFILL-MAS, S.; ALBINANA-GIMENEZ, N.; CLEMENTECASARES, P.; HUNDESA, A.; RODRIGUEZ-MANZANO, J.; ALLARD, A.; CALVO, M. \& GIRONES, R. 2006. Quantification and stability of human adenoviruses and polyomavirus JCPyV in wastewater matrices. Applied and Environmental Microbiology, 72: 7894-7896, http://dx.doi.org/10.1128/AEM.00965-06

BON, F.; AMBERT-BALAY, K.; GIRAUDON, H.; KAPLON, J.; LE GUYADER, S.; POMMEPUY, M.; GALLAY, A.; VAILLANT, V.; DE VALK, H.; CHIKHI-BRACHET, R.; FLAHAUT, A.; POTHIER, P. \& KOHLI, E. 2005. Molecular epidemiology of caliciviruses detected in sporadic and outbreak cases of gastroenteritis in France from December 1998 to February 2004. Journal of Clinical Microbiology, 43: 4659-4664, http://dx.doi.org/10.1128/JCM.43.9.4659-4664.2005

BOSCH,A. 1998. Human enteric viruses in the water environment: a minireview. International Microbiology, 1: 191-196.

BOSCH, J.; COLL, M.; PUIG, A.; ESPAÑOL, T.; IBÁÑEZ, V.M.; INFANTE, D. \& TORMO, R. 1991. Autoimmune hepatitis with fatal outcome. Journal of Pediatrics, 118: 823-824, http:// dx.doi.org/10.1016/S0022-3476(05)80058-7

BOSCH, A.; GUIX, S.; SANO, D. \& PINTÓ, R.M. 2008. New tools for the study and direct surveillance of viral pathogens in water. Current Opinion in Biotechnology, 19: 295-301, http:// dx.doi.org/10.1016/j.copbio.2008.04.006

BOXMAN, I.L.; VENNEMA, H.; JONKER, K.; BOER, E.D. \& KOOPMANS, M. 2006. Detection of noroviruses in shellfish in the Netherlands. International Journal of Food Microbiology, 108: 391-396, http://dx.doi.org/10.1016/j.ijfoodmicro.2006.01.002

BRUMMITT, C.F.; CHERRINGTON, J.M.; KATZENSTEIN, D.A.; JUNI, B.A.; VAN DRUNEN, N.; EDELMAN, C.; RHAME, F.S. \& JORDAN, M.C. 1988. Nosocomial adenovirus infections: molecular epidemiology of an outbreak due to adenovirus $3 \mathrm{a}$. Journal of Infectious Diseases, 158: 423-432, http://dx.doi. org/10.1093/infdis/158.2.423
BULL, R.A.; TU, E.T.; MCIVER, C.J.; RAWLINSON, W.D. \& WHITE, P.A. 2006. Emergence of a new norovirus genotype II.4 variant associated with global outbreaks of gastroenteritis. Journal of Clinical Microbiology, 44: 327-333, http://dx.doi. org/10.1128/JCM.44.2.327-333.2006

CABELLI, V.J.; DUFOUR, A.P.; LEVIN, M.A.; MCCABE, L.J. \& HABERMAN, P.W. 1979. Relationship of microbial indicators to health effects at marine bathing beaches. American Journal of Public Health, 69: 690-696, http://dx.doi.org/10.2105/ AJPH.69.7.690

CABELLI, V.J.; DUFOUR, A.P.; MCCABE, L.J. \& LEVIN, M.A. 1982. Swimming-associated gastroenteritis and water quality. American Journal of Epidemiology, 115: 606-616.

CALGUA, B.; MENGEWEIN, A.; GRUNERT, A.; BOFILLMAS, S.; CLEMENTE-CASARES, P.; HUNDESA, A.; WYNJONES, A.P.; LÓPEZ-PILA, J.M. \& GIRONES, R. 2008. Development and application of a one-step low cost procedure to concentrate viruses from seawater samples. Journal of Virological Methods, 153: 79-83, http://dx.doi.org/10.1016/j. jviromet.2008.08.003

CAMPOS, G.S.; MOREAU, V.H.; BANDEIRA, A.; BARBERINO, G.; ALMEIDA, P.F.; AMADOR, D.M.; DE LIMA, M.O. \& SARDI, S.I. 2008. Molecular detection and genetic diversity of norovirus in hospitalized young adults with acute gastroenteritis in Bahia, Brazil. Archives of Virology, 153: 1125-1129, http://dx.doi.org/10.1007/s00705-008-0078-x

CARDUCCI, A.; MORICI，P.; PIZZI，F.; BATTISTINI，R.; ROVINI, E. \& VERANI, M. 2008. Study of the viral removal efficiency in a urban 12 wastewater treatment plant. Water Science \& Technology, 58: 893-897, http://dx.doi.org/10.2166/ wst. 2008.437

CARVALHO-COSTA, F.A.; VOLOTÃO, E. de M.; DE ASSIS, R.M;. FIALHO, A.M.; DE ANDRADE, J.da S.; ROCHA, L.N.; TORT, L.F.; DA SILVA, M.F.; GÓMEZ, M.M.; DE SOUZA, P.M. \& LEITE, J.P. 2011. Laboratory-based rotavirus surveillance during the introduction of a vaccination program, Brazil, 20052009. The Pediatric Infectious Disease Journal, 30: S35-S41, http://dx.doi.org/10.1097/INF.0b013e3181fefd5f

CASTIGNOLleS, N.; PETIT, F.; MENDEL, I.; SIMON, L.; CATTOLICO, L. \& BUFFET-JANVRESSE, C. 1998. Detection of adenovirus in the waters of the Seine River estuary by nestedPCR. Molecular and Cellular Probes, 12: 175-180, http://dx.doi. org/10.1006/mcpr.1998.0166 
CASTILHO, J.G.; MUNFORD, V.; RESQUE, H.R.; FAGUNDES-NETO, U.; VINJÉ, J. \& RÁCZ, M.L. 2006. Genetic diversity of Norovirus among children with gastroenteritis in São Paulo State, Brazil. Journal of Clinical Microbiology, 44: 39473953, http://dx.doi.org/10.1128/JCM.00279-06

CDC (Center of Disease Control and Prevention). 2008. Rotavirus surveillance worldwide, 2001-2008. MMWR Morbidity and Mortality Weekly Report, 57: 1255-1257.

CHANDRAN, A.; FITZWATER, S.;ZHEN, A. \& SANTOSHAM, M. 2010. Prevention of rotavirus gastroenteritis in infants and children: rotavirus vaccine safety, efficacy, and potential impact of vaccines. Biologics: targets \& therapy, 4: 213-229, http:// dx.doi.org/10.2147/BTT.S6530

CHAPRON, C.D.; BALLESTER, N.A.; FONTAINE, J.H.; FRADES, C.N. \& MARGOLIN, A.B. 2000. Detection of astroviruses, enteroviruses, and adenovirus types 40 and 41 in surface waters collected and evaluated by the information collection rule and an integrated cell culture-nested PCR procedure. Applied and Environmental Microbiology, 66: 25202525, http://dx.doi.org/10.1128/AEM.66.6.2520-2525.2000

CHIBA, S.; NAKATA, S.; NAKAMURA, I.; TANIGUCHI, K.; URASAWA, S.; FUJINAGA, K. \& NAKAO, T. 1983. Outbreak of infantile gastroenteritis due to type 40 adenovirus. Lancet 2: 954-957, http://dx.doi.org/10.1016/S0140-6736(83)90463-4

CHO, H.B.; LEE, S.H.; CHO, J.C. \& KIM, S.J. 2000. Detection of adenoviruses and enteroviruses in tap water and river water by reverse transcription multiplex PCR. Canadian Journal of Microbiology, 46: 417-424, http://dx.doi.org/10.1139/w00-014

CIARLET, M.; HOFFMANN, C.; LORUSSO, E.; BASELGA, R.; CAFIERO, M.A.; BÁNYAI, K.; MATTHIJNSSENS, J.; PARREÑO, V.; DE GRAZIA, S.; BUONAVOGLIA, C. \& MARTELLA, V. 2008. Genomic characterization of a novel group A lamb rotavirus isolated in Zaragoza, Spain. Virus Genes, 37: 250-265, http://dx.doi.org/10.1007/s11262-008-0257-6

CLARK, B. \& MCKENDRICK, M. 2004. A review of viral gastroenteritis. Current Opinion in Infectious Diseases, 17: 461469, http://dx.doi.org/10.1097/00001432-200410000-00011

COHEN, J.I.; ROSENBLUM, B.; TICEHURST, J.R.; DAEMER, R.J.; FEINSTONE, S.M. \& PURCELL, R.H. 1987. Complete nucleotide sequence of an attenuated hepatitis A virus: comparison with wild-type virus. Proceedings of the National Academy of Sciences of the United States of America, 84: 2497-2501, http:// dx.doi.org/10.1073/pnas.84.8.2497

COLOMBA, C.; DE GRAZIA, S.; GIAMMANCO, G.M.; SAPORITO, L.; SCARLATA, F.; TITONE, L. \& ARISTA,
S. 2006. Viral gastroenteritis in children hospitalised in Sicily, Italy. European Journal of Clinical Microbiology \& Infectious Diseases, 25: 570-575, http://dx.doi.org/10.1007/s10096-0060188-x

CONAMA (Conselho Nacional do Meio Ambiente). 2000. Ministério do Meio Ambiente. Resolução $n^{\circ}$ 274, de 29 de novembro de 2000. Diário Oficial [da] República Federativa do Brasil, Poder Executivo, Brasília, DF.

CRAUN, G.F. 1992. Causes of waterborne outbreaks in the United States. Water Science \& Technology, 24: 17-20.

CRAUN, G.F.; CALDERON, R.L. \& CRAUN, M.F. 2005. Outbreaks associated with recreational water in the United States. International Journal of Environmental Health Research, 15: 243-262, http://dx.doi.org/10.1080/09603120500155716

CUTHBERT, J.A. 2001. Hepatits A: old and new. Clinical Microbiology Reviews, 14: 38-58, http://dx.doi.org/10.1128/ CMR.14.1.38-58.2001

D’ALESSIO, D.; MINOR, T.E.; ALLEN, C.I.; TSIATIS, A.A. \& NELSON, D.B. 1981. A study of the proportions of swimmers among well controls and children with enterovirus-like illness shedding or not shedding an enterovirus. American Journal of Epidemiology, 113: 533-541.

DE PAULA, V.S.; BAPTISTA, M.L.; LAMPE, E.; NIEL, C. \& GASPAR, A.M.C. 2002. Characterization of hepatitis A virus isolates from subgenotypes IA e IB Rio de Janeiro, Brazil. Journal of Medical Virology, 66: 22-27, http://dx.doi.org/10.1002/ jmv.2106

DE PAULA, V.S.; DINIZ-MENDES, L.; VILLAR, L.M.; LUZ, S.L.; SILVA, L.A.; JESUS, M.S.; DA SILVA, N.M. \& GASPAR, A.M. 2007. Hepatitis A virus in environmental water samples from the Amazon Basin. Water Research, 41: 1169-1176, http:// dx.doi.org/10.1016/j.watres.2006.11.029

DINGLE, J.H. \& LANGMUIR, A.D. 1968. Epidemiology of acute, respiratory disease in military recruits. American Review of Respiratory Disease, 97: 1-65.

DUIZER, E.; BIJKERK, P.; ROCKX, B.; DE GROOT,A.; TWISK, F. \& KOOPMANS, M. 2004. Inactivation of Caliciviruses. Applied and Environmental Microbiology, 70: 4538-4543, http:// dx.doi.org/10.1128/AEM.70.8.4538-4543.2004

EPA (ENVIRONMENTAL PROTECTION AGENCY). 1998. Drinking water contamination candidate list. Notice. Federal Regulation, 63: 10274-10287.

ESPINOSA, A.C.; MAZARI-HIRIART, M.; ESPINOSA, R.; MARURI-AVIDAL, L.; MÉNDES, E. \& ARIAS, C.F. 2008. 
Infectivity and genome persistence of rotavirus and astrovirus in groundwater and surface water. Water Research, 42: 2618-2628, http://dx.doi.org/10.1016/j.watres.2008.01.018

ESPINOSA, A.C.; ARIAS, C.F.; SÁNCHEZ-COLÓN, S. \& MAZARI-HIRIART, M. 2009. Comparative study of enteric viruses, coliphages and indicator bacteria for evaluating water quality in a tropical high-altitude system. Environmental Health, 8: 49, http://dx.doi.org/10.1186/1476-069X-8-49

ESTES, M.K.; BALL, J.M.; GUERRERO, R.A.; OPEKUN, A.R.; GILGER, M.A. \& PACHECO, S.S. 2000. Norwalk virus vaccines: Challenges and progress. Journal of Infectious Diseases, 181: S367-S373, http://dx.doi.org/10.1086/315579

ESTES, M. \& KAPIKIAN, A.Z. 2007. Rotaviruses. Pp 19171974. In: D.M. Knipe \& P.M. Howley (eds.). Fields Virology, 5th ed. Lippincott Williams \& Wilkins, Philadelphia, PA. 3091p.

FANKHAUSER， R.L.; MONROE， S.S.; NOEL， J.S.; HUMPHREY, C.D.; BRESEE, J.S.; PARASHAR, U.D.; ANDO, T. \& GLASS, R.I. 2002. Epidemiologic and molecular trends of "Norwalk-like Viruses" associated with outbreaks of gastroenteritis in the United States. Journal of Infectious Diseases, 186: 1-7, http://dx.doi.org/10.1086/341085

FEINSTONE, S.M.; KAPIKIAN, A.Z. \& PURCELI, R.H. 1973. Hepatitis A: detection by immune electron microscopy of a viruslike antigen associated with acute illness. Science, 182: 1026-1028, http://dx.doi.org/10.1126/science.182.4116.1026

FERREIRA，M.S.R.; XAVIER， M.P.T.P.; FUMIAN， T.M.; VICTORIA, M.; OLIVEIRA, S.A.; PENA, L.H.A.; LEITE, J.P. \& MIAGOSTOVICH, M.P. 2008. Acute gastroenteritis cases associated with noroviruses infection in the State of Rio de Janeiro. Journal of Medical Virology, 80: 338-344, http://dx.doi. org/10.1002/jmv.21059

FERREIRA, F.F.; GUIMARÃES, F.R.; FUMIAN, T.M.; VICTORIA, M.; VIEIRA, C.B.; LUZ, S.; SHUBO, T.; LEITE, J.P. \& MIAGOSTOVICH, M.P. 2009. Environmental dissemination of group A rotavirus: P-type, G-type and subgroup characterization. Water Science and Technology, 60: 633-642, http://dx.doi.org/10.2166/wst.2009.413

FERREIRA, M.S.; VICTORIA, M.; CARVALHO-COSTA, F.A. VIEIRA, C.B.; XAVIER, M.P.; FIORETTI, J.M.; ANDRADE, J.; VOLOTÃO, E.M.; ROCHA, M.; LEITE, J.P. \& MIAGOSTOVICH, M.P. 2010. Surveillance of norovirus infections in the state of Rio de Janeiro, Brazil 2005-2008. Journal of Medical Virology, 82: 1442-1448, http://dx.doi. org/10.1002/jmv.21831
FLEWETT, T.H.; BRYDEN, A.S. \& DAVIES, H. 1973. Letter: Virus particles in gastroenteritis. Lancet, 2: 1497, http://dx.doi. org/10.1016/S0140-6736(73)92760-8

FLEWETT, T.H. \& WOODE, G.N. 1978. The rotaviruses. Archives of Virology, 57: 1-23, http://dx.doi.org/10.1007/ BF01315633

FORMIGA-CRUZ, M.; TOFIÑO-QUESADA, G.; BOFILLMAS, S.; LEES, D.N.; HENSHILWOOD, K.; ALLARD, A.K.; CONDEN-HANSSON, A.C.; HERNROTH, B.E.; VANTARAKIS, A.; TSIBOUXI, A.; PAPAPETROPOULOU, M.; FURONES, M.D. \& GIRONES, R. 2002. Distribution of human virus contamination in shellfish from different growing areas in Greece, Spain, Sweden, and the United Kingdom. Applied and Environmental Microbiology, 68: 5990-5998, http:// dx.doi.org/10.1128/AEM.68.12.5990-5998.2002

FORMIGA-CRUZ, M.; ALLARD, A.K.; CONDENHANSSON, A.C.; HENSHILWOOD, K.; HERNROTH, B.E.; JOFRE, J.; LEES, D.N.; LUCENA, F.; PAPAPETROPOULOU, M.; RANGDALE, R.E.; TSIBOUXI, A.; VANTARAKIS, A. \& GIRONES, R. 2003. Evaluation of potential indicators of viral contamination in shellfish and their applicability to diverse geographical areas. Applied and Environmental Microbiology, 69: 1556-1563, http://dx.doi.org/10.1128/AEM.69.3.1556-1563.2003 FOUT, G.S.; MARTINSON, B.C.; MOYER, M.W. \& DAHLING, D.R. 2003. A multiplex reverse transcription-PCR method for detection of human enteric viruses in groundwater. Applied and Environmental Microbiology, 69: 3158-3164, http://dx.doi. org/10.1128/AEM.69.6.3158-3164.2003

FRETZ, R.; HERRMANN, L.; CHRISTEN, A.; SVOBODA, P.; DUBUIS, O.; VIOLLIER, E.H.; TANNER, M. \& BAUMGARTNER, A. 2005. Frequency of Norovirus in stool samples from patients with gastrointestinal symptoms in Switzerland. European Journal of Clinical Microbiology \& Infectious Diseases, 24: 214-216, http://dx.doi.org/10.1007/ s10096-005-1300-3

FROGGATT, P.C.; VIPOND, B.I.; ASHLEY, C.R.; LAMBDEN, P.R.; CLARKE, I.N. \& CAUL, E.O. 2004. Surveillance of norovirus infection in a study of sporadic childhood gastroenteritis in South West England and South Wales during one winter season (1999-2000). Journal of Medical Virology, 72: 307-311, http:// dx.doi.org/10.1002/jmv.10569

FUMIAN, T.M.; LEITE, J.P.; CASTELLO, A.A.; GAGGERO, A.; CAILlOU, M.S. \& MIAGOSTOVICH, M.P. 2010. Detection of rotavirus A in sewage samples using multiplex qPCR and an evaluation of the ultracentrifugation and adsorption-elution 
methods for virus concentration. Journal of Virological Methods, 170: 42-46, http://dx.doi.org/10.1016/j.jviromet.2010.08.017

GASSILLOUD, B.; SCHWARTZBROD, L. \& GANTZER, C. 2003. Presence of viral genomes in mineral water: a sufficient condition to assume infectious risk?. Applied and Environmental Microbiology, 69: 3965-3969, http:/dx.doi.org/10.1128/ AEM.69.7.3965-3969.2003

GENTRY, J.; VINJE, J.; GUADAGNOLI, D. \& LIPP, E.K. 2009. Norovirus distribution within an estuarine environment. Applied and Environmental Microbiology, 75: 5474-5480, http://dx.doi. org/10.1128/AEM.00111-09

GERBA, C.P.; GOYAL, S.M.; LABELLE, N.L.; CECH, I. \& BOGDAN, G.F. 1979. Failure of indicator bacteria to reflect the occurence of enterovirus in marine waters. American Journal of Public Health, 69: 1116-1119, http://dx.doi.org/10.2105/ AJPH.69.11.1116

GERBA, C.P.; GRAMOS, D.M. \& NWACHUKU, N. 2002. Comparative inactivation of enteroviruses and adenovirus 2 by UV light. Applied and Environmental Microbiology, 68: 51675169, http://dx.doi.org/10.1128/AEM.68.10.5167-5169.2002

GLASS, R.I ; NOEL, J.; ANDO, T.; FANKHAUSER, R.; BELLIOT, G.; MOUNTS, A.; PARASHAR, U.D. ; BRESEE, J.S. \& MONROE, S.S. 2000. The epidemiology of enteric caliciviruses from humans: a reassessment using new diagnostics. Journal of Infectious Diseases, 181: S254-S261, http://dx.doi. $\operatorname{org} / 10.1086 / 315588$

GOYAL, S.M.; ADAMS, W.N.; O’MALLEY, L. \& LEAR, D.W. 1984. Human pathogenics viruses at sewage sludge disposal sites in the middle atlantic region. Applied and Environmental Microbiology, 48: 758-763.

GRABOW, W.O.K. 2007. Overview of health-related water virology. Pp. 1-25. In: A. Bosch (ed.). Human viruses in water. Elsevier, Amsterdam, AS. 299p, http://dx.doi.org/10.1016/ S0168-7069(07)17001-4

GREENBERG, H.B. \& ESTES, M.K. 2009. Rotavirus: from pathogenesis to vaccination. Gastroenterology, 136: 1939-1951, http://dx.doi.org/10.1053/j.gastro.2009.02.076

GRIFFIN, D.W.; GIBSON, C.J. III; LIPP, E.K.; RILEY, K.; PAUL, J.H. III \& ROSE, J.B. 1999. Detection of viral pathogens by reverse transcriptase PCR and of microbial indicators by standard methods in the canals of the Florida Keys. Applied and Environmental Microbiology, 65: 4118-4125. Erratum in: Applied and Environmental Microbiology, 2000. 66: 876.
GUST, I.D. 1992. Epidemiological patterns of hepatitis A in different parts of the world. 10: S56-S58, http://dx.doi. org/10.1016/0264-410X(92)90544-T

HALL, T.A. 1999. BioEdit: a user-friendly biological sequence alignment editor and analysis program for Windows 95/98/NT.

Nucleic Acids Symposium Series, 41: 95-98.

HALLIDAY, M.L.; KANG, L.Y.; ZHOU, T.K.; HU, M.D.; PAN, Q.C.; FU, T.Y.; HUANG, Y.S. \& HU, S.L. 1991. An epidemic of hepatitis A attributable to the ingestion of raw clams in Shanghai, China. Journal of Infectious Diseases, 164: 852-859, http:// dx.doi.org/10.1093/infdis/164.5.852

HAMZA, I.A.; JURZIK, L.; STANG, A.; SURE, K.; UBERLA, K. \& WILHELM, M. 2009. Detection of human viruses in rivers of a densly-populated area in Germany using a virus adsorption elution method optimized for PCR analyses. Water Research, 43: 2657-2668, http://dx.doi.org/10.1016/j.watres.2009.03.020

HARAMOTO, E.; KATAYAMA, H.; OGUMA, K. \& OHGAKI, S. 2007. Recovery of naked viral genomes in water by virus concentration methods. Journal of Virological Methods, 142: 169-173, http://dx.doi.org/10.1016/j.jviromet.2007.01.024

HEIM, A.; EBNET, C.; HARSTE, G. \& PRING-AKERBLOM, P. 2003. Rapid and quantitative detection of human adenovirus DNA by real-time PCR. Journal of Medical Virology, 70: 228239, http://dx.doi.org/10.1002/jmv.10382

HERNANDEZ-MORGA, J.; LEON-FELIX, J.; PERAZAGARAY, F.; GIL-SALAS, B.G. \& CHAIDEZ, C. 2009. Detection and characterization of hepatitis A virus and Norovirus in estuarine water samples using ultrafiltration - RT-PCR integrated methods. Journal of Applied Microbiology, 106: 1579-1590, http://dx.doi. $\operatorname{org} / 10.1111 / \mathrm{j} .1365-2672.2008 .04125 . \mathrm{x}$

IKE, A.C.; BROCKMANN, S.O.; HARTELT, K.; MARSCHANG, R.E.; CONTZEN, M.C. \& OEHME, R.M. 2006. Molecular epidemiology of Norovirus in outbreaks of gatroenteritis in southwest Germany from 2001 to 2004. Journal of Clinical Microbiology, 44: 1262-1267, http://dx.doi. org/10.1128/JCM.44.4.1262-1267.2006

INEA (Instituto Estadual do Ambiente). 2009. Rio de Janeiro, Brasil. <www.inea.rj.gov.br/fma/lagoa-rodrigo-freitas>. (Acesso em 20/12/2009).

ITURRIZA-GOMARA， M.; WONG， C.; BLOME， S.; DESSELBERGER, U. \& GRAY, J. 2002. Molecular characterization of VP6 genes of human rotavirus isolates: correlation of genogroups with subgroups and evidence of 
independent segregation. Journal of Virology, 76: 6596-6601, http://dx.doi.org/10.1128/JVI.76.13.6596-6601.2002

JIANG, S. 2006. Human Adenoviruses in Water: Occurrence and Health Implications: A critical Review. Environmental Science \& Technology, 40: 7132-7140, http://dx.doi.org/10.1021/es060892o JOTHIKUMAR, N.; CROMEANS, T.L.; SOBSEY, M.D. \& ROBERTSON, B.H. 2005. Development and evaluation of a broadly reactive detection TaqMan assay for rapid detection of hepatitis A virus. Applied and Environmental Microbiology, 71: 3359-3363, http://dx.doi.org/10.1128/AEM.71.6.3359-3363.2005

KAPIKIAN, A.Z.; WYATT, R.G.; DOLIN, R.; THORNHILL, T.S.; KALICA, A.R. \& CHANOCK, R.M. 1972. Visualization by immune electron microscopy of a $27-\mathrm{nm}$ particle associated with acute infectious nonbacterial gastroenteritis. Journal of Virology, 10: $1075-1081$

KAGEYAMA, T.; KOJIMA, S.; SHINOHARA, M.; UCHIDA, K.; FUKUSHI, S.; HOSHINO, F.B.; TAKEDA, N. \& KATAYAMA, K. 2003. Broadly Reactive and Highly Sensitive Assay for Norwalk-Like Viruses Based on Real-Time Quantitative Reverse Transcription-PCR. Journal of Clinical Microbiology, 41: 15481557, http://dx.doi.org/10.1128/JCM.41.4.1548-1557.2003

KATAYAMA, H.; SHIMASAKI, A. \& OHGAKI, S. 2002. Development of a virus concentration method and its application to detection of enterovirus and norwalk virus from coastal seawater. Applied and Environmental Microbiology, 68: 10331039, http://dx.doi.org/10.1128/AEM.68.3.1033-1039.2002

KRAJDEN, M.; BROWN, M.; PETRASEK, A. \& MIDDLETON, P.J. 1990. Clinical features of adenovirus enteritis: a review of 127 cases. The Pediatric Infectious Disease Journal, 9: 636-641.

KUKKULA, M.; MAUNULA, L.; SILVENNOINEM, E.; VON BONDSDORF, C.V. \& JAATINEM, P. 1999. Outbreak of viral gastroenteritis due to drinking water contaminated by Norwallike viruses. Journal of Infectious Diseases, 180: 1771-1776, http://dx.doi.org/10.1086/315145

LA ROSA, G.; FONTANA, S.; DI GRAZIA, A.; IACONELLI M.; POURSHABAN, M. \& MUSCILLO, M. 2007. Molecular Identification and Genetic Analysis of Norovirus Genogroups I and II in Water Environments: Comparative Analysis of Different Reverse Transcription-PCR Assays. Applied and Environmental Microbiology, 73: 4152-4161, http://dx.doi. org/10.1128/AEM.00222-07

LEDNAR, W.M.; LEMON, S.M.; KIRKPATRICK, J.W.; REDFIELD, R.R.; FIELDS, M.L. \& KELLEY, P.W. 1985. Frequency of illness associated with epidemic hepatitis A virus infections in adults. American Journal of Epidemiology, 122: 226-233.

LEE, H. ; KIM, M. ; LEE, J.E. ; LIM, M. ; KIM, M. ; KIM, J.M. ; JHEONG, W.H. ; KIM, J. \& KO, G. 2011. Investigation of norovirus occurrence in groundwater in metropolitan Seoul, Korea. Science of the Total Environment, 409: 2078-2084, http:// dx.doi.org/10.1016/j.scitotenv.2011.01.059

LEITE, J.P.; CARVALHO-COSTA, F.A. \& LINHARES, A.C. 2008. Group A rotavirus genotypes and the ongoing Brazilian experience: a review. Memórias do Instituto Oswaldo Cruz, 103: $745-753$

LIN, Y.-P.; KAO, C.-L.; CHANG, S.-Y.; TANIGUCHI, K.; HUNG, P.-Y.; LIN, H.-C.; HUANG, L.M.; HUANG, H.H.; YANG, J.Y. \& LEE, C.N. 2008. Determination of human rotavirus VP6 genogroups I and II by reverse transcription-PCR. Journal of Clinical Microbiology, 46: 3330-3337, http://dx.doi. org/10.1128/JCM.00432-08

LINHARES, A.C.; PINHEIRO, F.P.; SCHMETZ, C.; MÜLLER, G. \& PETERS, D.L. 1977. Duovirus (rotavirus) em Belém do Pará. Revista do Instituto de Medicina Tropical de São Paulo, 19: 278-279.

MALUQUER DE MOTES, C.; CLEMENTE-CASARES, P.; HUNDESA, A.; MARTÍN, M. \& GIRONES, R. 2004. Detection of bovine and porcine adenoviruses for tracing the source of fecal contamination. Applied and Environmental Microbiology, 70: 1448-1454, http://dx.doi.org/10.1128/AEM.70.3.1448-1454.2004

MATTHIJNSSENS, J.; CIARLET, M.; HEIMAN, E.; ARIJS, I.; DELBEKE, T.; MCDONALD, S.M.; PALOMBO, E.A.; ITURRIZA-GÓMARA, M.; MAES, P.; PATTON, J.T.; RAHMAN, M. \& VAN RANST, M. 2008a. Full genome-based classification of rotaviruses reveals a common origin between human Wa-Like and porcine rotavirus strains and human DS-1like and bovine rotavirus strains. Journal of Virology, 82: 32043219, http://dx.doi.org/10.1128/JVI.02257-07

MATTHIJNSSENS, J.; CIARLET, M.; RAHMAN, M.; ATTOUI, H.; BÁNYAI, K.; ESTES, M.K.; GENTSCH, J.R.; ITURRIZAGÓMARA, M.; KIRKWOOD, C.D.; MARTELLA, V.; MERTENS, P.P.; NAKAGOMI, O.; PATTON, J.T.; RUGGERI, F.M.; SAIF, L.J.; SANTOS, N.; STEYER, A.; TANIGUCHI, K.; DESSELBERGER, U. \& VAN RANST, M. 2008b. Recommendations for the classification of group A rotaviruses using all 11 genomic RNA segments. Archives of Virology, 153: 1621-1629, http://dx.doi.org/10.1007/s00705-008-0155-1

MCMINN, P.C.; STEWART, J. \& BURRELL, C.J. 1991. A community outbreak of epidemic keratoconjunctivitis in central 
Australia due to adenovirus type 8. Journal of Infectious Diseases, 164: 1113-1118, http://dx.doi.org/10.1093/infdis/164.6.1113

MEIKLEJOHN, G. 1983. Viral respiratory disease at Lowry Air Force Base in Denver, 1952-1982. Journal of Infectious Diseases, 148: 775-784, http://dx.doi.org/10.1093/infdis/148.5.775

MELEG, E.; JAKAB, F.; KOCSIS, B.; BANYAI, K.; MELEGH, B. \& SZUCS, G. 2006. Human astroviruses in raw sewage samples in Hungary. Journal of Applied Microbiology, 101: 11231129, http://dx.doi.org/10.1111/j.1365-2672.2006.02997.x

MELNICK, J.L. 1947. Poliomyelitis virus in urban sewage in epidemic and non-epidemic times. American Journal of Hygiene, 45: 240-253.

MELNICK J.L. 1995. History and epidemiology of hepatitis A. Journal of Infectious Diseases, 171: S2-S8, http://dx.doi. org/10.1093/infdis/171.Supplement_1.S2

MENA, K.D. \& GERBA, C.P. 2008. Waterborne Adenovirus. Pp. 133-167. In: D.M. Whitacre, H.N. Nigg \& D.R. Doerge (eds.). Reviews of Environmental Contamination and Toxicology. Volume 198. Springer Science + Business, New York, NY, USA. 205p, http://dx.doi.org/10.1007/978-0-387-0964 7-6_4

MENDES, A.C.O. 2009. Monitoramento do vírus da hepatite A na lagoa Rodrigo de Freitas, do município do Rio de Janeiro, RJ. Dissertação de Mestrado. Instituto Oswaldo Cruz/Fundação Oswaldo Cruz. Rio de Janeiro, RJ. 98p.

METCALF, T.G.; MELNICK, J.L. \& ESTES, M.K. 1995. Environmental virology: from detection of virus in sewage and water by isolation to identification by molecular biology - a trip of over 50 years. Annual Review of Microbiology, 49: 461-487, http://dx.doi.org/10.1146/annurev.mi.49.100195.002333

MIAGOSTOVICH, M.P.; FERREIRA, F.F.M.; GUIMARAES, F.R.; FUMIAN, T.M.; DINIZ-MENDES, L.; LUZ, S.L.B.; SILVA, L.A. \& LEITE, J.P.G. 2008. Molecular Detection and Characterization of Gastroenteritis Viruses Occurring Naturally in the Stream Waters of Manaus, Central Amazonia, Brazil. Applied and Environmental Microbiology, 74: 375-382, http:// dx.doi.org/10.1128/AEM.00944-07

MINISTÉRIO DA SAÚDE. 2004. Secretaria de Vigilância em Saúde, Coordenação- Geral de Vigilância em Saúde Ambiental. Portaria $\mathrm{n}^{\circ} 518$, de 25 de março de 2004. Diário Oficial [da] República Federativa do Brasil, Poder Executivo, Brasília, DF.

MORENO, S.; ALVARADO, M.V.; BERMÚDEZ, A. \& GUTIÉRREZ, M.F. 2009. Phylogenetic analysis indicates human origin of rotavirus and hepatitis A virus strains found in the drinking water of western Colombia. Biomédica, 29: 209-217.
NAINAN, O.V.; XIA, G.; VAUGHAN, G. \& MARGOLIS, H.S. 2006. Diagnosis of hepatitis a virus infection: a molecular approach. Clinical Microbiology Reviews, 19: 63-79, http:// dx.doi.org/10.1128/CMR.19.1.63-79.2006

NAKAGOMI, T.; CORREIA, J.B.; NAKAGOMI, O.; MONTENEGRO, F.M.U.; CUEVAS, L.E.; CUNLIFFE, N.A. \& HART, C.A. 2008. Norovirus infection among children with acute gastroenteritis in Recife, Brazil: disease severity is comparable to rotavirus gastroenteritis. Archives of Virology, 153: 957-960, http://dx.doi.org/10.1007/s00705-008-0060-7

OKADA, M.; OGAWA, T.; KAIHO, I. \& SHINOZAKI, K. 2005. Genetic analysis of noroviruses in Chiba Prefecture, Japan, between 1999 and 2004. Journal of Clinical Microbiology, 43: 4391-4401, http://dx.doi.org/10.1128/JCM.43.9.4391-4401.2005

PAPAPETROPOULOU, M. \& VANTARAKIS, A.C. 1998. Detection of adenovirus outbreak at a municipal swimming pool by nested PCR amplification. Journal of Infection, 36: 101-103, http://dx.doi.org/10.1016/S0163-4453(98)93414-4

PARASHAR, U.D.; LI, J.F.; CAMA, R.; DEZALIA, M.; MONROE, S.S.; TAYLOR, D.N.; FIGUEROA, D.; GILMAN, R.H. \& GLASS, R.I. 2004. Human caliciviruses as a cause of severe gastroenteritis in Peruvian children. Journal of Infectious Diseases, 190: 1088-1092, http://dx.doi.org/10.1086/423324

PATEL, M.M.; WIDDOWSON, M.-A.; GLASS, R.I.; AKAZAWA, K.; VINJÉ, J. \& PARASHAR, U.D. 2008. Systematic literature review of role of noroviruses in sporadic gastroenteritis. Emerging Infectious Diseases, 14: 1224-1231, http://dx.doi.org/10.3201/eid1408.071114

PATEL, M.M.; HALL, A.J.; VINJÉ, J. \& PARASHAR, U.D. 2009. Noroviruses: A comprehensive review. Journal of Clinical Virology, 44: 1-8, http://dx.doi.org/10.1016/j.jcv.2008.10.009

PAYNE, S.B.; GRILLI, E.A.; SMITH, A.G. \& HOSKINS, T.W. 1984. Investigation of an outbreak of adenovirus type 3 infection in a boys' boarding school. The Journal of Hygiene, 93: 277-283, http://dx.doi.org/10.1017/S0022172400064809

PEREZ-VARGAS, J.; ISA, P.; LOPEZ, S. \& ARIAS, C.F. 2006. Rotavirus vaccine: early introduction in Latin America-risks and benefits. Archives of Medical Research, 37: 1-10, http://dx.doi. org/10.1016/j.arcmed.2005.06.004

PINA, S.; PUIG, M.; LUCENA, F.; JOFRE, J. \& GIRONES, R. 1998. Viral pollution in the environment and in shellfish: human 11 adenovirus detection by PCR as an index of human viruses. Applied and Environmental Microbiology, 64: 3376-3382. 
PINA, S.; BUTI, M.; JARDÍ, R.; CLEMENTE-CASARES, P.; JOFRE, J. \& GIRONES, R. 2001. Genetic analysis of hepatitis A virus strains recovered from the environment and from patients with acute hepatitis. Journal of General Virology, 82: 2955-2963.

POND, K. 2005. Water recreation and disease. Plausibility of Associated Infections: Acute Effects, Sequelae and Mortality. IWA Publishing, London, GL. 239p.

PRADO, T.; SILVA, D.M.; GUILAYN, W.C.; ROSE, T.L.; GASPAR, A.M. \& MIAGOSTOVICH, M.P. 2011. Quantification and molecular characterization of enteric viruses detected in effluents from two hospital wastewater treatment plants. Water Research, 45: 1287-1297, http://dx.doi.org/10.1016/j. watres.2010.10.012

PROJETO AMBIENTAL LAGOA LIMPA. 2009. Rio de Janeiro, Brasil. < www.lagoalimpa.com.br/oprojeto>. (Acesso em 20/12/2009).

PUIG, M.; JOFRE, J.; LUCENA, F.; ALLARD, A.; WADELL, G. \& GIRONES, R. 1994. Detection of adenoviruses and enteroviruses in polluted waters by nested PCR amplification. Applied and Environmental Microbiology, 60: 2963-2970.

PUSCH, D.; OH, D.Y.; WOLF, S.; DUMKE, R.; SCHROTERBOBSIN, U.; HOHNE, M.; RÖSKE, I. \& SCHREIER, E. 2005. Detection of enteric viruses and bacterial indicators in German environmental waters. Archives of Virology, 150: 929-947, http:// dx.doi.org/10.1007/s00705-004-0467-8

RAJAL, V.B.; MACSWAIN, B.S.; THOMPSON, D.E.; LEUTENEGGER, C.M. \& WUERTZ, S. 2007. Molecular quantitative analysis of human viruses in California stormwater. Water Research, 41: 4287-4298, http://dx.doi.org/10.1016/j. watres.2007.06.002

RIBEIRO, L.R.; GIUBERTI, R.S.O.; BARREIRA, D.M.P.G.; SAICK, K.W.; LEITE, J.P.G.; MIAGOSTOVICH, M.P. \& SPANO, L.C. 2008. Hospitalization due to norovirus and genotypes of rotavirus in pediatric patients, state of Espírito Santo. Memórias do Instituto Oswaldo Cruz, 103: 201-206, http://dx.doi.org/10.1590/S0074-02762008000200013

RICHARDSON, S.; GRIMWOOD, K.; GORRELL, R.; PALOMBO, E.; BARNES, G. \& BISHOP, R. 1998. Extended excretion of rotavirus after severe diarrhoea in young children. Lancet, 351: 1844-1848, http://dx.doi.org/10.1016/S01406736(97)11257-0

RIGOTTO, C.; VICTORIA, M.; MORESCO, V.; KOLESNIKOVAS, C.K.; CORRÊA, A.A.; SOUZA, D.S.; MIAGOSTOVICH, M.P.; SIMÕES, C.M. \& BARARDI, C.R.
2010. Assessment of adenovirus, hepatitis A virus and rotavirus presence in environmental samples in Florianopolis, South Brazil. Journal of Applied Microbiology, 109: 1979-1987, http://dx.doi. $\operatorname{org} / 10.1111 / \mathrm{j} .1365-2672.2010 .04827 . x$

ROBERTSON, B.H.; JANSEN, R.W.; KHANNA, B.; TOTSUKA, A.; NAINAN, O.V.; SIEGL, G.; WIDELL, A.; MARGOLIS, H.S.; ISOMURA, S.; ITO, K.; ISHIZU, T.; MOTITSUGU, Y. \& LEMON, S.M. 1992. Genetic relatedness of hepatitis A virus strains recovered from different geographical regions. Journal of General Virology, 73: 1365-1377, http:// dx.doi.org/10.1099/0022-1317-73-6-1365

ROSE, M.A.; DHAR, A.K.; BROOKS, H.A.; ZECCHINI, F. \& GERSBERG, R.M. 2006. Quantitation of hepatitis A virus and enterovirus levels in the lagoon canals and Lido beach of Venice, Italy, using real-time RT-PCR. Water Research, 40: 2387-2396, http://dx.doi.org/10.1016/j.watres.2006.03.030

SANTOS, N. \& HOSHINO, Y. 2005. Global distribution of rotavirus serotypes/genotypes and its implication for the development and implementation of an effective rotavirus vaccine. Reviews in Medical Virology, 15: 29-56, http://dx.doi. org/10.1002/rmv.448

SANTOS, N. \& SOARES, C. 2008. Viroses entéricas. Pp. 160166. In: N.S.O. Santos; M.T.V. Romanos \& M.D. Wigg (eds.). Introdução à Virologia Humana. 2 edição. Guanabara Koogan, Rio de Janeiro, RJ. 532p.

SCHETS, F.M.; DE RODA HUSMAN, A.M. \& HAVELAAR, A.H. 2010. Disease outbreaks associated with untreated recreational water use. Epidemiology and Infection, 10: 1-12, http://dx.doi.org/10.1017/S0950268810002347

SEYFRIED, P.L.; TOBIN, R.S.; BROWN, N.E. \& NESS, P.F. 1985. A prospective study of swimming-related illness. I. Swimming-associated health risk. American Journal of Public Health, 75: 1068-1070, http:/dx.doi.org/10.2105/ AJPH.75.9.1068

SILVA, A.M.; VIEIRA, H.; MARTINS, N.; GRANJA, A.T.; VALE, M.J. \& VALE, F.F. 2010. Viral and bacterial contamination in recreational waters: a case study in the Lisbon bay area. Journal of Applied Microbiology, 108: 1023-1031, http://dx.doi. org/10.1111/j.1365-2672.2009.04503.x

SKRABER, S.; GASSIOLLOUD, B.; SCHWARTZBROD, L. \& GANTZER, C. 2004. Survival of infectious Poliovirus-1 in river water compared to the persistence of somatic coliphages, thermotolerant coliforms and Poiliovirus-1 genome. Water Research, 38: 2927-2933, http://dx.doi.org/10.1016/j. watres.2004.03.041 
SOARES, C.C.; SANTOS, N.; BEARD, R.S.; ALBUQUERQUE, M.C.; MARANHÃO, A.G.; ROCHA, L.N.; RAMÍREZ, M.L.; MONROE, S.S.; GLASS, R.I. \& GENTSCH, J. 2007. Norovirus detection and genotyping for children with gastroenteritis, Brazil. Emerging Infectious Diseases, 13: 1244-1246, http://dx.doi. org/10.3201/eid1308.070300

TAMURA, K.; DUDLEY, J.; NEI, M. \& KUMAR, S. 2007. MEGA4: Molecular Evolutionary Genetics Analysis (MEGA) software version 4.0. Molecular Biology and Evolution, 24: 1596-1599, http://dx.doi.org/10.1093/molbev/msm092

THOMPSON, J.D.; HIGGINS, D.G. \& GIBSON, T.J. 1994. CLUSTAL W: improving the sensitivity of progressive multiple sequence alignment through sequence weighting, position-specific gap penalties and weight matrix choice. Nucleic Acids Research, 22: 4673-4680, http://dx.doi.org/10.1093/nar/22.22.4673

THORNTON, A.C.; JENNINGS-CONKLIN, K.S. \& MCCORMICK, MI. 2004. Noroviruses: agents in outbreaks of acute gastroenteritis. Disaster Management \& Response, 2: 4-9, http://dx.doi.org/10.1016/j.dmr.2003.11.001

VAIDYA, S.R.; CHITAMBAR, S.D. \& ARANKALLE, VA. 2002. Polymerase chain reaction-based prevalence of hepatitis $\mathrm{A}$, hepatitis $\mathrm{E}$ and TT viruses in sewage from an endemic area. Journal of Hepatology, 37: 131-136, http:/dx.doi.org/10.1016/ S0168-8278(02)00106-X

VAN HEERDEN, J.; EHLERS, M.M.; VAN ZYL, W.B. \& GRABOW, H.O.K. 2003. Incidence of adenoviruses in raw and treated water. Water Research, 37: 3704-3708, http://dx.doi. org/10.1016/S0043-1354(03)00245-8

VICTORIA, M.; CARVALHO-COSTA, F.Q.; HEINEMANN, M.B.; LEITE, J.P. \& MIAGOSTOVICH, M. 2007. Prevalence and molecular epidemiology of noroviruses in hospitalized children with acute gastroenteritis in Rio de Janeiro, Brazil, 2004. The Pediatric Infectious Disease Journal, 26: 602-606, http:// dx.doi.org/10.1097/INF.0b013e3180618bea

VICTORIA, M.; GUIMARÃES, F.R.; FUMIAN, T.M.; FERREIRA, FF.; VIEIRA, C.B., SHUBO, T.; LEITE, J.P. \& MIAGOSTOVICH, M.P. 2010a. One year monitoring of Norovirus in a Sewage Treatment Plant in Rio de Janeiro, Brazil. Journal of Water and Health, 8: 158-165, http://dx.doi. org/10.2166/wh.2009.012

VICTORIA, M.; RIGOTTO, C.; MORESCO, V.; DE ABREU CORRÊA, A.; KOLESNIKOVAS, C.; LEITE, J.P.; MIAGOSTOVICH, M.P. \& BARARDI, C.R. 2010b. Assessment of norovirus contamination in environmental samples from Florianópolis City, Southern Brazil. Journal of Applied
Microbiology, 109: 231-238, http://dx.doi.org/10.1111/j.13652672.2009.04646.x

VIDAL, R.; SOLARI, V.; MAMAMI, N.; JIANG, X.; VOLLAIRE, J.; ROESSLER, P.; PRADO, V.; MATSON, D.O. \& O'RYAN, M.L. 2005. Caliciviruses and Foodborne Gastroenteritis, Chile. Emerging Infectious Diseases, 11: 11341136, http://dx.doi.org/10.3201/eid1107.041062

VIEIRA, C.B. 2010. Deteç̧ão, quantificação e caracterização molecular de virus gastroentéricos na Lagoa Rodrigo de Freitas, 2007-2008. Dissertação de Mestrado. Instituto Oswaldo Cruz/ Fundação Oswaldo Cruz, Rio de Janeiro, RJ, Brasil. 101p.

VIEIRA, C.B.; MENDES, A.C.O.; GUIMARÃES, F.R.; FUMIAN, T.M.; LEITE, J.P.G.; GASPAR, A.M.C. \& MIAGOSTOVICH, M.P. Detection of enteric viruses in recreational waters of an urban lagoon in the city of Rio de Janeiro, Brazil. Memórias do Insituto Oswaldo Cruz. (in press).

VILLAR, L.M.; LAMPE, E.; MEYER, A. \& GASPAR, A.M. 2004. Genetic variability of hepatitis A virus isolates in Rio de Janeiro: implications for the vaccination of school children. Brazilian Journal of Medical and Biology Research, 37: 17791787, http://dx.doi.org/10.1590/S0100-879X2004001200003

VILLAR, L.M.; de PAULA, V.S.; DINIZ-MENDES, L.; LAMPE, E. \& GASPAR, A.M. 2006. Evaluation of methods used to concentrate and detect hepatitis A virus in water samples. Journal of Virological Methods, 137: 169-176, http://dx.doi. org/10.1016/j.jviromet.2006.06.008

VINJÉ, J.; HAMIDJAJA, R.A. \& SOBSEY, M.D. 2004. Development and application of a capsid VP1 (region D) based reverse transcription PCR assay for genotyping of genogroup I and II noroviruses. Journal of Virological Methods, 116: 109-117, http://dx.doi.org/10.1016/j.jviromet.2003.11.001

VITRAL, C.L.; YOSHIDA, C.F.; LEMOS, E.R.; TEIXEIRA, C.S. \& GASPAR, A.M. 1998. Age-specific prevalence of antibodies to hepatitis $\mathrm{A}$ in children and adolescents from Rio de Janeiro, Brazil, 1978 and 1995. Relationship of prevalence to environmental factors. Memórias do Instituto Oswaldo Cruz, 93: 1-5, http://dx.doi.org/10.1590/S0074-02761998000100001

VITRAL, C.L.; GASPAR, A.M. \& SOUTO, F.J. 2006. Epidemiological pattern and mortality rates for hepatitis A in Brazil, 1980-2002--a review. Memórias do Instituto Oswaldo Cruz, 101: 119-127, http://dx.doi.org/10.1590/S007402762006000200001

VITRAL, C.L.; SOUTO, F.J. \& GASPAR, A.M. 2008. Changing epidemiology of hepatitis A in Brazil: reassessing immunization 
policy. Journal of Viral Hepatitis, 15: 22-25, http://dx.doi. org/10.1111/j.1365-2893.2008.01024.x

WARD, R.L.; KNOWLTON, D.R. \& WINSTON, P.E. 1986. Mechanism of inactivation of enteric viruses in fresh water. Applied and Environmental Microbiology, 52: 450-459.

WIDDOWSON, M.A.; SULKA, A.; BULENS, S.N.; BEARD, R.S.; CHAVES, S.S.; HAMMOND, R.; SALEHI, E.D.; SWANSON, E.; TOTARO, J.; WORON, R.; MEAD, P.S.; BRESEE, J.S.; MONROE, S.S. \& GLASS, R.I. 2005. Norovirus and foodborne disease, United States, 1991-2000. Emerging Infectious Diseases, 11: 95-102, http://dx.doi.org/10.3201/ eid1101.040426

WINOKUR, P.L.; MCLINDEN, J.H. \& STAPLETON, J.T. 1991. The hepatitis A virus polyprotein expressed by a recombinant vaccinia virus undergoes proteolytic processing and assembly into viruslike particles. Journal of Virology, 65: 5029-5036.

WINOKUR, P.L. \& STAPLETON, J.T. 1992. Immunoglobulin prophylaxis for hepatitis A. Clinical Infectious Diseases, 14: 580586, http://dx.doi.org/10.1093/clinids/14.2.580

WONG, M.; KUMAR, L.; JENKINS, T.M.; XAGORARAKI, I.; PHANIKUMAR, M.S. \& ROSE, J.B. 2009. Evaluation of public health risks at recreational beaches in Lake Michigan via detection of enteric viruses and a human-specific bacteriological marker. Water Research, 43: 1137-1149, http://dx.doi.org/10.1016/j. watres.2008.11.051

WYN-JONES, A.P.; PALLIN, R.; DEDOUSSIS, C.; SHORE, J. \& SELLWOOD, J. 2000. The detection of small roundstructured viruses in water and environmental materials. Journal of Virological Methods, 87: 99-107, http://dx.doi.org/10.1016/ S0166-0934(00)00157-9

WYN-JONES,A.P.; CARDUCCI,A.; COOK, N.; D'AGOSTINO, M.; DIVIZIA, M.; FLEISCHER, J.; GANTZER, C.; GAWLER, A.; GIRONES, R.; HÖLLER, C.; DE RODA HUSMAN, A.M.; KAY, D.; KOZYRA, I.; LÓPEZ-PILA, J.; MUSCILLO, M.; NASCIMENTO, M.S.; PAPAGEORGIOU, G.; RUTJES, S.; SELLWOOD, J.; SZEWZYK, R. \& WYER, M. 2011. Surveillance of adenoviruses and noroviruses in European recreational waters. Water Research, 45: 1025-1038, http:// dx.doi.org/10.1016/j.watres.2010.10.015

ZENQ, S.Q.; HALKOSALO, A.; SALMINEN, M.; SZAKAL, E.D.; PUUSTINEN, L. \& VESIKARI, T. 2008. One-step quantitative RT-PCR for the detection of rotavirus in acute gastroenteritis. Journal of Virological Methods, 153: 238-240, http://dx.doi.org/10.1016/j.jviromet.2008.08.004
ZHENG, D.P.; ANDO, T.; FANKHAUSER, R.L.; BEARD, R.S.; GLASS, R.I. \& MONROE, S.S. 2006. Norovirus classification and proposed strain nomenclature. Virology, 346: 312-323, http:// dx.doi.org/10.1016/j.virol.2005.11.015

Submetido em: 31/08/2011

Aceito em: 21/11/2011 